\title{
LA ERA DE LAS REDES: SERVICIOS PÚBLICOS, GRANDES EMPRESAS Y FINANZAS INTERNACIONALES EN LAS CIUDADES MEXICANAS A PRINCIPIOS DEL SIGLO XX
}

\author{
Gerardo Martínez Delgado \\ Universidad de Guanajuato
}

\begin{abstract}
Z n 1911 se constituyó en Toronto la Barcelona Traction, Light and Power Company, impulsada por el ingeniero estadounidense Frederick Pearson y un grupo de inversionistas canadienses. La empresa era sólo una entre las múltiples compañías que el grupo tenía activadas en Canadá, Estados Unidos, México, Cuba, Jamaica, Brasil, Bolivia y Chile, y su conformación se inscribe dentro de uno de los momentos paradigmáticos de la expansión capitalista a escala mundial. ${ }^{1}$
\end{abstract}

Fecha de recepción: 27 de mayo de 2019

Fecha de aceptación: 7 de febrero de 2020

1 Horacio Capel, "Innovación técnica, gestión empresarial y financiación en el capitalismo global de comienzos del siglo xx. Los casos de Brazilian Traction y Barcelona Traction”, Introducción al Simposio Internacional “Globalización, innovación y construcción de redes técnicas urbanas en América y Europa, 1890-1930”, Universidad de Barcelona, enero de 2012, 36 pp. [en línea] http:// www.ub.edu/geocrit/cCapel_Innovacion_intro.pdf [27 de enero de 2015]. Berenguer Gangolells Alseda, "La evolución del modelo de implantación de empresas eléctricas de F. S. Pearson”, ponencia presentada en el Simposio Internacional "Globalización, innovación y construcción de redes técnicas urbanas en América y Europa, 1890-1930”, Universidad de Barcelona, enero 
En México, para entonces, las empresas soportadas por esos intereses estaban agrupadas en la Mexican Light and Power Company (MLPC), la cual compartía con el binomio Banco Central Mexicano-Compañía Bancaria de Fomento y Bienes Raíces, y con la Sociedad Pearson \& Son (cada una con sus aliadas, subsidiarias o competidoras medianas y pequeñas) una participación muy relevante en la construcción de infraestructura o prestación de servicios públicos urbanos, como redes de agua potable, drenaje, pavimentación, telefonía, electricidad y tranvías en las ciudades más grandes y atractivas para la inversión en el país.

El camino seguido hacia esa concentración estuvo sembrado de huellas opacas, dispersas, esquivas, difíciles de identificar, de redes de intereses que conectaban a muchos niveles y se anudaban a muy largas distancias. Según el mirador que se elija, colocados en la primera década del siglo xx se pueden encontrar raíces 30, 40 o 50 años atrás. Como se trató de la coincidencia de innumerables procesos involucrados en la expansión de redes económicas y de mercados financieros internacionales, las posibilidades de estudio se multiplican, complican y tienden a especializarse.

En México han existido investigaciones relevantes sobre la industria eléctrica desde la década de 1940, y desde la historiografía se han recogido buenos frutos en los últimos 20 años. $^{2}$ Recientemente se han hecho más evidentes las conexiones entre

de 2012, 11 pp. http://www.ub.edu/geocrit/Simposio/cGangolells_Laevolucion.pdf

2 Entre los primeros, Galarza, La industria eléctrica en México y Tamayo, "La generación de energía”. Véanse también, como ejemplos, el balance de Ana Paula Solís Rojas, "La generación eléctrica en México: una aproximación cuantitativa, 1880-1930”, Simposio Internacional: Globalización, innovación y construcción de redes técnicas urbanas en América y Europa, 1890-1930, Universidad de Barcelona, enero 2012, 19 pp. [en línea] http://www.ub.edu/ geocrit/Simposio/cSolis_Lageneracion.pdf [27 de enero de 2015], pp. 4-5; el libro de LIEHR y TORRES (coords.), Las compañias eléctricas extranjeras, y el de GÁmEz (coord.), Electricidad. 
las empresas mexicanas y otras en Brasil, España, Canadá o Estados Unidos, gracias a notables aportes desde esos países que sin embargo no siempre han logrado un diálogo provechoso entre sí, y a grandes esfuerzos de historia empresarial comparada. ${ }^{3}$ Otro tanto puede decirse de la historia empresarial y bancaria, que mediante algunos grupos de investigación bien identificables ha caracterizado los diferentes momentos de desarrollo de las empresas y ha desentrañado los mecanismos con los que se organizaban y operaban por todo el mundo.

Respecto a los servicios públicos, en México se avanzó primero en el alumbrado público, aunque casi siempre de manera tangencial, pues el punto de interés estaba en la generación de energía eléctrica. Las preguntas a veces se dirigían al sector de la minería y los procesos por los que su explotación se transformó. En muchas exploraciones las conexiones empresariales y productivas que se buscaban eran las de la geografía minera. ${ }^{4} \mathrm{El}$ tema del agua potable también ha tenido un importante desarrollo en los últimos 20 años; aquí se ha pasado de la identificación de comportamientos generales, principalmente sobre el carácter de su prestación, pública o privada, a abordajes de casos muy puntuales y cada vez más representativos. ${ }^{5}$ Existen varias historias particulares sobre los servicios públicos de alumbrado y tranvía, pero no pocas veces contadas al margen, y otras sobre la introducción o construcción de infraestructura para redes de agua, drenaje, pavimentación o teléfono que se conocen más parcialmente, como producto de los acercamientos específicos que se han hecho a cada ciudad. ${ }^{6}$

\footnotetext{
3 Véanse los resultados de los cuatro simposios internacionales promovidos por el grupo Geocrítica: http://www.ub.edu/geocrit/menu.htm, y también Armstrong y Nelles, "La empresa corporativa”.

4 Véase por ejemplo Coll-Hurtado y SÁnchez, "Minería y electricidad".

${ }^{5}$ Entre los trabajos pioneros: BirRichaga, "Las empresas de agua potable”.

${ }^{6}$ Leticia Gamboa esbozó hace tiempo la ruta de investigación, pero su trabajo se ha aprovechado más para estudiar otros casos particulares que para buscar
} 
El presente texto propone una revisión amplia, una interpretación más general apoyada en la copiosa literatura que cubre las distintas temáticas, pero privilegiando aquí el componente urbano, es decir, considerando el crecimiento de muchas ciudades de México y con ello de sus posibilidades y necesidades de servicios modernos. Se subraya la relación entre los servicios públicos, que en las investigaciones suelen fragmentarse o invisibilizarse, pero que en la práctica iban de la mano en los intereses de las empresas, como una estrategia para maximizar sus beneficios.

Siguiendo a Mira Wilkins, Reinhard Liehr y Mariano Torres han distinguido dos grandes momentos en que los servicios públicos se revelaron como una necesidad para las administraciones públicas urbanas y se ofertaron por las empresas. En una primera fase, que inició en la década de 1880, las primeras buscaron la instalación de alumbrado público eléctrico y de redes de agua con tubería de fierro, en parte por un prurito de modernidad y en parte por las exigencias reales que iba imponiendo el crecimiento de las ciudades: fue el tiempo de las pequeñas empresas de inversionistas locales, de extranjeros establecidos y familiarizados con el entorno, y de las medianas compañías extranjeras en su primera expansión. La segunda fase se hizo notoria con el cambio de siglo, y en ella irrumpieron en el escenario las grandes empresas nacionales e internacionales. En el sector eléctrico una de sus principales modalidades fue la de free standing companies (en adelante FSC), ${ }^{7}$ es decir, empresas establecidas en un país -Canadá, Estados Unidos o Inglaterra

relación entre ellos. GамвоA, "El financiamiento".

7 Wilkins, Liehr y Torres han definido a una FsC como "una empresa establecida en un país con el propósito de desarrollar actividades fuera de ese país”, con una oficina matriz reducida, "con el objetivo de hacerse de capital por medio de la venta de acciones y bonos en la bolsa” e invertir el capital en el exterior por medio de subsidiarias, "generalmente mediante la adquisición de operaciones o concesiones ya existentes”. LIEHR y TorREs, Las compañias eléctricas, p. 17. 
normalmente- con el propósito de desarrollar actividades en otro, es decir, en México. En otros sectores también se valieron de FSC, pero en general, y acorde a las reglas de expansión capitalista, el capital dilató sus inversiones, zonas de interés y coberturas complejizando sus estructuras y vínculos para la financiación: a veces fueron alianzas entre intereses organizados de diferente manera, otras fueron "grupos de inversión internacional”, otras multinacionales. ${ }^{8}$

Puede proponerse un momento de transición en la segunda década del siglo xx, provocado en México por la irrupción del movimiento revolucionario, que paralizó en las administraciones municipales la celebración de nuevos contratos, trastocó la prestación de los ya existentes, y afectó sensiblemente la estabilidad de las empresas, a veces llevándolas a la quiebra.

El artículo está construido a partir de información bibliográfica dispersa -en la que a veces se confunden o no se identifican las conexiones empresariales-, estadísticas generales, documentos públicos que incluyen contratos, escrituras y correspondencia; se basa en hemerografía, en el seguimiento de trayectorias personales y redes familiares y empresariales, y en la construcción de cartografía temática que soporta muchos de los argumentos.

Es posible que algunos de los trazos gruesos de esta historia resulten conocidos, aunque sólo lo sean desde la perspectiva económica. Aún más, y como han dicho Armstrong y Nelles, "en los albores del siglo xx los servicios públicos en todo el mundo capitalista llegaron a ser proporcionados por tipos parecidos de organizaciones". ${ }^{9}$ A pesar de todo ello, los detalles y las interpretaciones son importantes. En las siguientes líneas puede obtenerse una imagen más ordenada de su funcionamiento empresarial y de sus características como un sector en constante reacomodo. Los trazos más delgados de esta historia aportan

\footnotetext{
8 Jones, “Business Enterprises”, pp. 583 y ss.

9 Armstrong y Nelles, "La empresa corporativa”.
} 
algo más: un panorama de historias empresariales que se fueron anudando y que ponen el acento en las dificultades y vaivenes que tuvieron al menos unas 40 ciudades en el país para contar con servicios públicos.

\section{SERVICIOS PÚBLICOS Y PROYECTOS DE CAMBIO URBANO: \\ EL TIEMPO DE LAS PEQUEÑAS EMPRESAS DE AGUA \\ Y ELECTRICIDAD}

Entre los últimos años del siglo xix y los primeros del xx, las ciudades mexicanas en particular, pero casi todas alrededor del mundo, experimentaron complejos procesos de transformación impulsados por diversos motores: uno de los promotores fundamentales del cambio lo fueron las élites, y uno de los elementos que impulsaron con más entusiasmo fue el de la introducción de servicios públicos modernos. ${ }^{10}$ Se trataba de introducir nuevas formas de cubrir viejas necesidades, es decir, de incorporar las posibilidades de las tecnologías desarrolladas desde finales del siglo XviII que se iban perfeccionando y permitían no sólo llevar agua a las casas, como hasta entonces, sino mejorar su potabilidad y llevarla a través de una red de tubería de fierro; y no sólo iluminar, comunicar y transportar, sino hacerlo mediante fuerza eléctrica. Así, se trataba de aprovechar las tuberías de fierro, válvulas y herramientas para construir redes de agua potable y drenaje; el petróleo y sus derivados para iluminar y recubrir las calles; los dínamos, motores, bombillos y cableados para producir energía eléctrica y emplearla como fuerza motriz e iluminación, además de muchos otros recursos, instrumentos, máquinas y aparatos.

10 Para algunas precisiones sobre el término y los principios jurídicos de los servicios públicos puede verse con provecho AÑonve, Servicios públicos, pp. 82-91. 
El proceso de introducción de estos servicios-que marcan un punto de inflexión en la historia de los asentamientos urbanos, que definen la ciudad actual, y sin los cuales no podemos entender las urbes que habitamos- tuvo una de sus etapas decisivas al final del porfiriato, cuando se consolidaron grandes grupos de empresas, tres bien identificables junto con algunos de menores dimensiones. Con las redes de apoyo que formaron y con su influencia, estas empresas guiaron y presionaron la instalación de servicios en varias decenas de urbes mexicanas, atractivas por su número de población o vocación para ofertar esta clase de servicios. Por entonces, en ese círculo se contaban al menos 20 que tenían más de 30000 habitantes, 12 o 15 más que superaban los 15000 pobladores, además de las ciudades mineras o portuarias.

Al terminar 1899, según un recuento de Rafael Arizpe, 56 ciudades y poblaciones en México contaban con alumbrado público eléctrico en algunas de sus calles, pero en julio de 1900 había información de 65 localidades. Las lámparas que se instalaron en la capital en diciembre de 1881 mostraron al resto del país la mejora que apenas tres años antes había sido introducida en París, tras décadas de experimentación y de muy lentos avances en la materia. En 1884 Guanajuato hizo lo propio, en 1885 Guadalajara, y entre 1888 y 1890 se fueron sumando Puebla, Morelia, San Luis Potosí, Tacubaya, Toluca, volviéndose decenas a la vuelta de pocos años. ${ }^{11}$

Los centros mineros y las industrias fueron los primeros en aprovechar las ventajas de la energía eléctrica como fuerza motriz, pero casi al mismo tiempo todas las poblaciones de medianas dimensiones (en promedio más de 20000 habitantes) encontraron en el alumbrado eléctrico una continuidad natural a los anteriores sistemas de iluminación pública, primero con

${ }^{11}$ Los datos no son exactos, pero sí indicativos. Arizpe registró por ejemplo la introducción del servicio en Guanajuato en el año 1898, cuando en realidad la ciudad contó con él 14 años antes, en 1884. Véanse ArizPe, Estadística, pp. 94-97; MeYer, "La ciudad de Guanajuato”, p. 53. 
sebo, luego manteca, gas, gasolina y petróleo y, aunque no en todos los lugares que se instaló parecía estrictamente necesario, se volvió un atractivo y un negocio prometedor.

Los momentos y las circunstancias de introducción fueron muy variables. Guanajuato y Oaxaca, que ocupaban un lugar intermedio entre las ciudades más pobladas, contaron con algunas lámparas eléctricas en sus calles poco después que la ciudad de México. Veracruz, el puerto principal del país, las tuvo hasta 1895, apenas un año antes que Córdoba, que tenía una población mucho menor. Pachuca, a pesar de la importancia de sus minas, no tuvo servicio para la ciudad sino a partir de 1892. En la tabla 1 no se enlistan otras capitales o ciudades importantes, como Chihuahua, Saltillo, Colima o Irapuato, pues a pesar de que contaron con la instalación antes de 1899, no sabemos la fecha con precisión.

Como han hecho notar Liehr y Torres, “al comienzo, los constructores de plantas y sistemas eran compañías pequeñas establecidas por empresarios regionales, tanto mexicanos como inmigrantes", 12 casi siempre ligados a otros negocios como la minería o alguna rama industrial en que aplicaban la fuerza eléctrica. La otra gran modalidad de empresa en los primeros años fue la de las compañías medianas de Estados Unidos que avanzaron hacia el sur (en 1900 había en Estados Unidos unas 3000 empresas de electricidad $)^{13}$ y ofrecieron sus servicios en una, dos u ocasionalmente más ciudades. Lo más frecuente era la combinación de circunstancias.

En Morelia, por ejemplo, en 1888 se contrató a una empresa de capital estadounidense, con sede en la ciudad de México, para instalar las primeras lámparas eléctricas; en 1896 el gobierno rescindió el contrato y se hizo cargo a su cuenta y riesgo, pero a

12 Liehr y Torres, Las compañias eléctricas, p. 9. Armstrong y Nelles, "La empresa corporativa”.

13 Williams, Historia de la tecnología, vol. 4, p. 104. 


\section{Tabla 1}

LAS 32 CIUDADES MEXICANAS CON ALUMBRADO PÚBLICO ELÉCTRICO ANTES DE 1899 SEGÚN EL AÑO Y LA POSICIÓN DEMOGRÁFICA QUE OCUPABAN EN EL CONJUNTO DEL PAÍS

\begin{tabular}{llll}
\hline Ciudad & Año & Ciudad & Año \\
\hline México (1) & 1881 & Pachuca (12) & 1892 \\
Guanajuato (15) & $1884 *$ & Tampico (30) & 1893 \\
Oaxaca (13) & 1884 & Veracruz (8) & 1895 \\
Guadalajara (2) & 1885 & Orizaba (17) & 1895 \\
Puebla (3) & 1888 & Culiacán (39) & 1895 \\
San Luis Potosí (5) & 1888 & Mazatlán (29) & 1895 \\
Morelia (10) & 1888 & Córdoba (64) & 1896 \\
Tacubaya (14) & 1888 & Uruapan (47) & 1896 \\
Monterrey (4) & 1889 & Monclova (112) & 1896 \\
Toluca (21) & 1889 & Parras (137) & 1896 \\
Aguascalientes (9) & $1890 *$ & Durango (20) & 1897 \\
Querétaro (19) & 1890 & Zamora (31) & 1897 \\
Chilpancingo (44) & 1890 & León (7) & 1898 \\
Zacatecas (24) & 1891 & Torreón (18) & 1898 \\
Concepción del Oro (26) & 1891 & Jalapa (26) & 1898 \\
Mérida (6) & 1892 / & Celaya (23) & 1899 \\
& $1883 *$ & & \\
\hline
\end{tabular}

Fuente: para los años de instalación: ArIzPe, Estadística, pp. 94-97. Se señalan con * los datos no consignados por Arizpe, que están tomados, para Guanajuato, de Meyer, "Ciudad”, p. 53; para Aguascalientes, de Martínez, Cambio; para Mérida, de Fuentes y Rosado, “Mérida”, y Durán-Merk, “Imaginando el progreso”, pp. 1 y 7; para Oaxaca, de Lira y Calderón, “Capital”, p. 252. Arizpe tomó sus datos de la documentación enviada por diversas autoridades a la Comisión Mexicana para la Exposición de París, en 1900. Como él mismo reconoció, sus datos no son totalmente exactos, el año de instalación puede no corresponder y seguramente faltan en la relación varias ciudades importantes. Para el lugar de cada población en el conjunto de las ciudades con más habitantes del país, correspondiente a 1910: Tercer Censo de Población de los Estados Unidos Mexicanos, capítulo XIV: Poblaciones de la República. 
partir de 1905 le entregó la concesión del servicio al empresario local Herculano Ibarrola. ${ }^{14}$ En Oaxaca la empresa encargada fue por algún tiempo Zorrilla y Compañía, de capital local, con la cual contrataban los servicios tanto el ayuntamiento -para los edificios públicos y las calles- como los particulares - para las fábricas y domicilios. ${ }^{15}$

En Mérida la ruta fue relativamente distinta, aunque en realidad solo varió ligeramente el orden de los participantes. La primera iniciativa provino de un empresario local, que importó un motor de vapor con el que en 1883 pudo generar energía para unas pocas lámparas de la plaza mayor. Tiempo después, en 1892, se pudo prestar un mejor servicio con el concurso de personajes locales asociados con la Thompson Houston International Electric Company, de Boston. En Mérida y en todas partes una nota característica fue la de la inestabilidad empresarial. Aquí, en 1899 el servicio público fue concesionado a la Compañía Yucateca de Luz y Fuerza Eléctrica, financiada por la familia Peón, que tenía como su proveedora de equipo a la casa alemana Siemens \& Halske. Con la experiencia que la Siemens tenía en la concesión del servicio en la ciudad de México, en 1901 se aventuró a quedarse con la planta de Mérida y la operó por algunos años. ${ }^{16}$

La estadounidense Interstate Gas and Waterworks, de San Luis Misuri, ${ }^{17}$ probó suerte en Durango y Aguascalientes. En esta última la inauguración del sistema tuvo lugar el 15 de septiembre de $1890 .{ }^{18}$ Tampoco aquí el negocio resultó tan redituable como lo había calculado la Interstate, que en 1902 logró

\footnotetext{
14 Pérez, Empresarios, pp. 175-187. URIBE, Morelia, pp. 32-35.

15 LiRA, “Obra y servicios”, pp. 252-253.

16 Durán-Merk, “Imaginando el progreso”, pp. 6 y ss. Aunque hay algunas imprecisiones en el texto, se toma como referencia de algunas tendencias en la operación del servicio.

17 El Republicano (3 nov. 1889).

18 El Republicano (3 nov. 1889).
} 
traspasar su planta y su contrato a la Compañía de Luz y Fuerza Eléctricas de Aguascalientes, empresa constituida expresamente por Carlos Doerr, un estadounidense que había iniciado años atrás sus aventuras empresariales en suelo mexicano, no casualmente alrededor de intereses mineros. ${ }^{19}$ Una segunda empresa, la Compañía Eléctrica de Aguascalientes, la constituyó en 1904 el inglés Juan Douglas, quien entonces tenía casi una década en la ciudad al frente de un molino de trigo que fue, como en otros casos, un antecedente natural para explotar las posibilidades de la energía eléctrica que era tan útil en la industria. ${ }^{20}$ Por seis años, estos dos personajes, que no tardarían en convertirse en los dos extranjeros con más influencia en la localidad, convivieron con sus productoras de energía eléctrica y la de Douglas se encargó del sistema de tranvías.

Un fenómeno paralelo al de la expansión del alumbrado eléctrico en las ciudades fue el de la instalación de tuberías, de fierro y en red, para conducir agua -potable- a los domicilios. Asociada a los grandes valores de la “salubridad pública”, el “embellecimiento" y la "comodidad del vecindario”, casi todas las poblaciones, independientemente de su tamaño y recursos, hicieron esfuerzos para contar con esta mejora, señaladamente desde la década de $1880 .{ }^{21}$

En las discusiones ventiladas en muchas ciudades del país había consenso a favor de implantar redes de agua, según el modelo

19 AHEA, PN, Not. Alberto M. Dávalos, libro 195, 1902, fs. 224f-227v. AHEA, PN, Not. Alberto M. Dávalos, libro 199, fs. 20f-21f. Gómez, “Extranjeros”, pp. 59-61. AHEA, PN, Not. Mariano Dávalos, libro 132, es. 111, fs. 2f-3f. GómEz y RodRíguez, 1982, pp. 114-116. El Observador (1 jun. 1907), núm. 49. AMA, H, 329.37.

20 AHEA, PN, Not. Alberto M. Dávalos, libro 199, es. 116, fs. 164f-167f. Sagredo, "Informe", El Republicano (20 nov. 1903 y 20 dic. 1903). El Republicano (10 y 17 ene. 1904).

21 BirrichagA, “Las empresas de agua potable”, pp. 200 y ss. Silva, “Ario de Rosales”, p. 21. Bustamante, “Un perfil”, p. 65. 
que se había diseñado en Londres un siglo atrás. ${ }^{22}$ Este sistema marcaba una diferencia radical con la distribución "en línea” que se había acostumbrado; si hasta entonces el agua se conducía por cañerías independientes y lineales que iban desde las cajas de agua hasta las fuentes públicas, una red como las que hoy se utilizan conecta varias líneas entre sí, formando circuitos que se controlan con válvulas, permitiendo manejar a discreción las zonas y las cantidades de agua a distribuir. ${ }^{23}$ Además, la incorporación de bombas de vapor o eléctricas, las tuberías de hierro y la construcción de depósitos de agua o la perforación de pozos permitían como nunca antes ampliar el número de domicilios favorecidos.

Puebla tuvo una instalación en línea, con tubos de hierro, en 1855. ${ }^{24}$ El concesionario se comprometió a llevar la cañería "hasta el umbral de todas las casas y fuentes públicas”. Se trató de un caso temprano, pues por entonces dominaba en las ciudades la conducción de líquido mediante acequias, a veces tapadas o con tubos de barro, pero las más a cielo abierto, o a través de acueductos, en los que se invertían cuantiosas sumas para su siempre difícil mantenimiento.

El siguiente paso, el abasto en red, se dio por las posibilidades técnicas para bombear agua desde grandes depósitos, o para excavar pozos y armar sofisticados sistemas de conducción. Además, debe subrayarse, fue apareciendo en el horizonte la contratación de deuda, un mecanismo prácticamente inédito con el que las autoridades municipales podían acceder a recursos adicionales a los propios, que una y otra vez se habían mostrado insuficientes, aún más ante la creciente necesidad y la demanda social del agua.

22 Birrichaga, "Las empresas de agua potable", pp. 194-195 y 200-201.

23 Birrichaga, "Las empresas de agua potable”, pp. 193-195.

24 Birrichaga, "Las empresas de agua potable”, pp. 200-202. 
En 1895 en Oaxaca se planteó seriamente construir un sistema moderno de distribución de agua. A la convocatoria de concesión se presentaron dos proyectos, uno del ingeniero Rodolfo Franco y del hijo del exgobernador Albino Zertuche, y otro de los extranjeros Alberto E. Milliken y James Gillespie Clow. Las propuestas eran ambiciosas y costosas e implicaban concesiones que iban de los 50 a los 80 años. Al final el gobierno no se decidió por ninguna y las obras fueron postergadas, ${ }^{25}$ pero el caso es ilustrativo del tipo de actores, de las dificultades económicas y de las condiciones técnicas que implicaba la formación de los circuitos que superaran las limitadas dotaciones a que estaban acostumbrados los habitantes de las ciudades.

En Aguascalientes la construcción de la primera red de abastecimiento de agua resultó relativamente tardía y modesta, pero económica. Después de varios intentos, en 1898 se contrató a la compañía de los extranjeros Guillermo Paterson y Donald Stewart, con sede en la ciudad de México, y las obras se ejecutaron entre noviembre de 1898 y mayo de $1899 .{ }^{26}$ Por una cantidad que pudo sufragar el Ayuntamiento, sin deudas ni enormes obras, se surtieron con tubería no solo las fuentes públicas, sino que se ofrecieron mercedes a los vecinos, 400 de los cuales presentaron solicitudes y obtuvieron su conexión particular antes de $1904 . .^{27}$

Como se verá, en Oaxaca, en Aguascalientes y en otras ciudades al final de la primera década del siglo xx se echaron a andar proyectos muy ambiciosos. En Zacatecas, en cambio, antes de la Revolución no se concretó ningún contrato importante que involucrara empréstitos comerciales ni una red que al menos pretendiera ofrecer una cobertura amplia a los domicilios de la población. A pesar de ello, el caso es interesante por el gran

25 SÁnchez, Gobierno municipal, pp. 115 y ss.

26 AHEA, $P N, 1898$.

27 AMA, $H$, Aguas, 6.24 y 250.13. AHEA, $P L, 89,16$. 
número de propuestas que se hicieron, el perfil de sus participantes y los alcances que buscaban. Diversos trabajos han documentado que entre 1890 y 1910 hasta seis iniciativas distintas pasaron por la revisión del cabildo. Entre los involucrados estaban comerciantes o profesionistas locales, como el doctor Julián Ruiz -propietario de una botica-, varios particulares con domicilio en la ciudad de México, una compañía inglesa y un ingeniero estadounidense. De todos, y por la información que se tiene a la vista, solo en 1901 se planteó por primera vez un proyecto para dotar a la ciudad de un sistema en red, pues todo lo anterior correspondía a las viejas ideas que en todas partes se habían elucubrado para contar con más agua y conducirla a las fuentes públicas.

En 1906 apareció en el escenario John Lee Stark, un ingeniero estadounidense que estaba por terminar unos trabajos deficientes pero innovadores en Morelia, los cuales había iniciado en 1903 y se encaminaban a filtrar y garantizar la potabilidad del agua. Stark firmó un contrato con el gobierno de Zacatecas, pero en 1909 se canceló; al parecer hubo uno más en 1910, pero tampoco llegó a tener efecto. Así, sin mayores gastos y con intervenciones menores, Zacatecas se mantuvo sin un cambio radical en su dotación de agua. El Ayuntamiento compró por su cuenta bombas eléctricas para contar con más líquido, a la vez que siguió recurriendo a estrategias como en el pasado, ya obteniendo el líquido que se desaguaba de las minas o el que se hacía conducir en tanques por ferrocarril. ${ }^{28}$

El éxito fue muy desigual, pero desde minúsculas poblaciones como Tlaxcala (capital de un estado) con sus 3000 habitantes en 1910, Ario de Rosales, las medianas como Morelia, Oaxaca o Toluca, hasta las grandes como Puebla, Guadalajara y la ciudad

28 Véase Medina, El tránsito urbano, pp. 128-134; Alfaro, La ciudad en torno al agua, pp. 183-199; Hurtado, "La ciudad sedienta", p. 89; Noriega, Más allá de la minería, pp. 190. 
de México, todas procuraron la formación de redes de agua y cuando no fue posible se conformaron con promover por diversos medios la "salubridad pública, el embellecimiento y la comodidad de su vecindario" con estas mejoras. ${ }^{29}$

$\mathrm{Al}$ acercarse el fin del siglo xIx se estaba cumpliendo en México el primer ciclo de creación de empresas de servicios públicos, el de las compañías pequeñas que servían a una ciudad y a lo más a su área de influencia, o las medianas que crecían rápidamente en un adecuado contexto geográfico (la existencia de una fuerte corriente de agua que permitiera invertir en una hidroeléctrica) o económico (la necesidad de generar fuerza para la explotación minera o para las industrias textiles o alimenticias, por ejemplo). A partir de ese momento se conoció el despegue, las inversiones agresivas, la reorganización, el reagrupamiento, las alianzas y los mecanismos institucionales para que las pequeñas empresas fueran o trataran de ser progresivamente absorbidas por otras más grandes.

\section{CIUDADES EN CRECIMIENTO, EMPRESAS EN EXPANSIÓN. \\ NUEVAS AMBICIONES Y NUEVAS POSIBILIDADES \\ TECNOLÓGICAS Y FINANCIERAS}

A lo largo de la primera década del siglo, muchas urbes tuvieron un importante crecimiento demográfico, especialmente las del norte, enganchadas por el ferrocarril a las redes de la pujante economía estadounidense, urbanizándose casi de la noche a la mañana: Torreón tenía 200 habitantes en 1892, 13800 en 1900 y 34300 en 1910; Gómez Palacio dio el salto de ranchería a población de 40000 almas; Saltillo pasó en la primera década del siglo xx de 24000 a 35000 ; Monterrey de 62000 a 78000 ; Hermosillo de 10000 a 14000 . En el mismo periodo Veracruz pasó de 29000 a 48000 , Mérida de 46000 a más de 62000 y

29 Bustamante, “Un perfil”, p. 65 
Aguascalientes aumentó casi 30\%, pasando de cerca de 35 a 45000 habitantes. Tampico, Chihuahua, Mazatlán y otras crecían también a buen ritmo. En 1910 Puebla rozaba los 100000 pobladores, Guadalajara los superaba y la ciudad de México casi alcanzaba medio millón. ${ }^{30}$

En conjunto, en los años finales del porfiriato, 28\% de la población del país residía en localidades de más de 2500 habitantes y una red de 20 ciudades de más de 30000 pobladores se articulaba sobre el territorio (véase el mapa 1). ${ }^{31}$ Fueron años definitivos en el cambio de ropajes de las ciudades: se amplió la plantación de alamedas y la modificación de muchas plazas por unas de gusto burgués; se llenaron las calles de alambres de telégrafos, teléfonos, electricidad y tranvías; se construyeron edificios más acordes a los principios de salubridad (panteones, rastros y hospitales), y aparecieron o se multiplicaron por las calles comerciales nuevos giros: ferreterías, relojerías, joyerías, bancos, hoteles, almacenes de ropa, restaurantes, abarrotes importados, estudios fotográficos, cines, cervecerías, expendios de petróleo, neverías, salones de patinar, boliches, hipódromos o distribuidoras de materiales para construcción, hasta automóviles. ${ }^{32}$

En términos urbanos la presión demográfica demandaba mejores servicios y mayor cobertura. En términos técnicos las posibilidades crecían continuamente: la energía producida con el aprovechamiento de caídas de agua, por ejemplo, revolucionó las oportunidades. Hasta entonces, la producción de electricidad seguía dependiendo de la generación de vapor con agua calentada por carbón; alrededor de 1890 las hidroeléctricas brindaron la posibilidad de sustituir el combustible fósil y permitieron generar grandes cantidades de energía susceptible de transportarse a grandes distancias; la primera gran hidroeléctrica se había

\footnotetext{
30 Connolly, El contratista, pp. 104-105.

31 Series Históricas INEGI, 1895-1995, www.inegi.gob.mx (consultadas en julio de 2005).

32 Martínez, Cambio y proyecto urbano.
} 


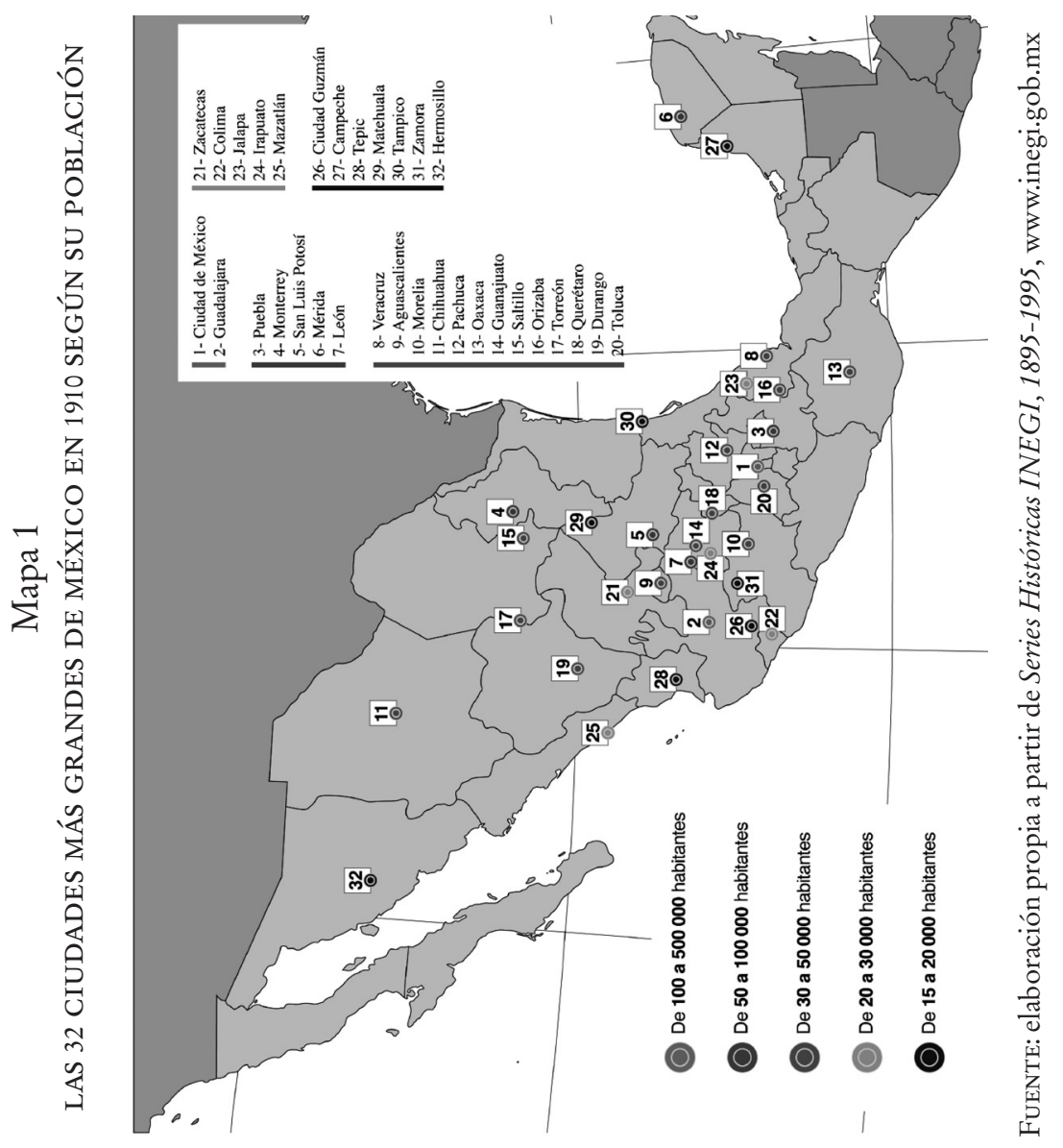


empezado a instalar en el Niágara en $1886 .{ }^{33}$ A lo anterior se añadió un elemento clave: el capital internacional en forma de crédito para la construcción. Como ha dicho Osterhammel, "La exportación de capital fue en lo esencial una innovación de la segunda mitad del siglo xIx", a partir de 1850, pero en particular después de 1870 se crearon las instituciones y los instrumentos en los países acreedores y en los deudores. ${ }^{34}$

En México y en otros países el paso decisivo para vincularse con los mercados internacionales ocurrió realmente hasta la primera década del siglo xx, con la reforma monetaria de 1905, que sustituyó el patrón plata por el patrón oro. ${ }^{35}$ Se trató de una medida de homogeneización entre sistemas monetarios que dieron estabilidad, ampliaron los vínculos y permitieron incrementar el flujo de capitales europeos al país. Institucionalmente un elemento clave lo eran los bancos hipotecarios, que a partir de 1897 eran en México -por lo menos teóricamente- los únicos facultados para ofrecer préstamos a largo plazo (como los necesarios para financiar grandes obras públicas), mediante la emisión de bonos, que se garantizaban con el valor de las propiedades gravadas o con el respaldo de finanzas públicas. ${ }^{36}$ Aunque existían sólo dos bancos hipotecarios, además de permisos especiales concedidos a otros bancos e instituciones financieras, "el total de los préstamos hipotecarios de los bancos -ha escrito Paolo Riguzzi- creció 6.5 veces entre 1900 y 1910, pero se desarrolló, de forma concentrada, esencialmente después de la reforma monetaria de 1905, que, al anular el riesgo de la depreciación de

33 Derry y Williams, Historia de la tecnología, v. 3, pp. 908-909.

34 Osterhammel, La transformación, pp. 1036-1038.

35 Antes, en 1887, México había reingresado al mercado de capitales después de mucho tiempo alejado por su insolvencia. Riguzzi, "Las relaciones de la banca alemana”, p. 112.

36 Paolo Riguzzi, "Sistema financiero y crédito agrícola en México, 18971913”, ponencia presentada en el Congreso de la Asociación Mexicana de Historia Económica, octubre de 2004, pp. 2-8. 
la plata, permitió la venta de los bonos hipotecarios mexicanos en los mercados extranjeros". ${ }^{37}$

La historiografía sigue discutiendo el desempeño económico del país en los primeros diez años del siglo xx, por ejemplo, las implicaciones del cambio al patrón oro, sus restricciones y efectos dispares, el impacto de la crisis estadounidense de 1907, o las limitaciones del crédito hipotecario. Los debates apuntan a evaluar las posibilidades de crecimiento o los obstáculos de la economía, el ritmo de exportaciones e importaciones del país, la inmediatez o no de los efectos de la crisis internacional, la contracción de los ingresos del estado o la caída de las inversiones. ${ }^{38}$

Frente a estas posiciones, está claro que en los primeros diez años del siglo hubo un incremento sostenido en el financiamiento de obras públicas en las ciudades mexicanas, como se demuestra más adelante. Así, los banqueros holandeses, alemanes, ingleses y franceses encontraron en este y otros países la posibilidad de extender sus inversiones, de modo que formaron innumerables sociedades destinadas a operar en México, e inyectaron recursos de consideración en los bancos mexicanos. ${ }^{39}$ Entre 1905 y 1911 el crédito hipotecario fue financiado desde las bolsas europeas, y "un grupo de grandes bancos franceses adquirió el control e inyectó considerablemente recursos que impulsaron extraordinariamente el volumen de negocios hipotecarios" ${ }^{40}$

Como se ha visto, al iniciar el siglo xx muchas ciudades tenían pequeñas empresas y modestos servicios de alumbrado y agua potable, organizados o construidos por el saber técnico y con las inversiones de locales, de extranjeros radicados en el país o de compañías foráneas de medianos alcances. Las bases estaban

37 Paolo Riguzzi, “Sistema financiero", p. 8.

38 Véase, por ejemplo, AnaYa, "La crisis internacional”, pp. 155-158.

39 OÑate, "La crisis", pp. 191-193. Ludlow, “La formación”, p. 150. TopiK, "When Mexico".

40 Paolo Riguzzi, “Sistema financiero”, pp. 6-8. RiguzzI, "Las relaciones de la banca alemana”, pp. 128 y 130. 
sentadas para un siguiente paso, para mejorar los servicios, ampliarlos e integrarlos, para fusionar empresas a partir de la experiencia ganada con capitales internacionales que ofrecían una alternativa a la imposibilidad crónica de las finanzas municipales y estatales.

Empresas en expansión, capitales internacionales a disposición, ciudades en crecimiento y convergencia de nuevas formas de cubrir viejas necesidades urbanas fueron el marco natural para desencadenar una serie de complejas negociaciones entre los distintos niveles de gobierno y los capitales que, a veces con simple espíritu de especulación, buscaron participar en la obtención de concesiones y contratos para prestar y construir obras y servicios públicos.

Hay que insistir: las grandes empresas del periodo no sólo se concentraron en los ferrocarriles, la explotación y beneficio de minerales, la extracción de petróleo, los bancos, las industrias textil, alimentaria, cervecera, de papel, o el comercio. También las hubo en un renglón amplio y complejo como el de los servicios públicos. Las listas de las compañías más importantes en México hacia 1910 consignan el vigor de las dedicadas a la electricidad, el transporte urbano y las telecomunicaciones, pero ocultan el dinamismo de los servicios públicos en su conjunto y el proceso de concentración que estaban sufriendo en esos años. ${ }^{41}$

\author{
LA CASA SCHÖNDUBE \& NEUGEBAUER \\ Y LA COMPAÑÍA BANCARIA DE FOMENTO Y \\ BIENES RAÍCES-BANCO CENTRAL MEXICANO
}

En términos expositivos el camino a la expansión puede ilustrarse siguiendo, en primer lugar, la trayectoria de Enrique Schöndube y sus socios (una historia que bien merece contarse aparte y con detalle), ligándola a los mecanismos de formación

${ }^{41}$ Ceceña, México en la órbita imperial, pp. 86-94. 
y operación del Banco Central Mexicano y la Compañía Bancaria de Fomento y Bienes Raíces S.A. Se trata de dos conjuntos empresariales diferentes, de origen, naturaleza, alcances y soportes financieros desiguales, pero que se entrelazaron de varias formas y que, junto con otros pocos, destacaron por su expansión y por su diversificación: en ambos casos participaron en obras y contratos que atendían servicios diferentes, llegaron a muchas ciudades en varias regiones del país, y penetraron en las empresas menores para potencializar su experiencia y conocimiento de los sectores.

El suyo fue, como en los otros dos casos que aquí se estudian, el resultado de la unión entre técnicos, especialistas actualizados en los adelantos tecnológicos, grandes comercializadores, agentes, políticos locales, poderosos empresarios nacionales o extranjeros, e inversionistas y compradores de bonos en las capitales financieras del mundo.

Enrique Schöndube, un alemán nacido en 1861, inició en un eslabón aparentemente modesto pero clave: desde 1894 estableció en México una casa comisionista independiente que distribuía de forma exclusiva los productos de la fábrica Allgemeine Elektricitäts Gesellschaft (en adelante AEG). ${ }^{42}$ A su almacén llegaban desde Alemania y otros lugares las máquinas, motores, turbinas, generadores, dínamos, calderas, transformadores, bombas y toda clase de herramientas y materiales eléctricos que vendía o instalaba lo mismo en teatros que en comercios, fábricas textiles o en compañías locales de generación de electricidad. Una relación no exhaustiva da cuenta de sus ventas de maquinaria hasta 1910 en al menos 18 estados, incluyendo compras en Casas Grandes, Hermosillo, Parras, Saltillo, Torreón, Zacatecas, Monterrey, Tampico, Veracruz, Orizaba, Guadalajara, Zamora, Dolores Hidalgo y Chilpancingo. ${ }^{43}$

\footnotetext{
42 Liehr y Torres, "Formas y estrategias de expansión”, pp. 209-214.

${ }^{43}$ El Mundo Ilustrado (6 feb. 1910), pp. 23-24.
} 
Pronto, con el capital reunido en su agencia comisionista Schöndube empezó a invertir en otras áreas del sector. Desde al menos 1899 se acercó a Guadalajara, donde obtuvo una concesión para utilizar el río Santiago en uno de sus puntos y empezó a invertir en la generación de electricidad. ${ }^{44}$ Hacía poco tiempo que los especuladores y los empresarios avispados estaban solicitando concesiones para aprovechar las corrientes de agua con las cuales se podía generar electricidad, y Schöndube tuvo especial olfato para ello. ${ }^{45}$ En 1904 hizo un intento por establecer una planta de electricidad en la ciudad de Colima, pero sus condiciones no fueron tan atractivas como las de los empresarios locales que obtuvieron el contrato. ${ }^{46}$ Antes, entre 1900 y 1901 buscó con empeño la formación de una fábrica de explosivos y en este u otro negocio entró en competencia con el empresario francés Ernesto Pugibet. ${ }^{47}$

Sin duda era para entonces un personaje bien relacionado con las altas esferas del poder en México, tenía trato con gobernadores y ministros, pero su carrera dio un giro en 1905, cuando se asoció con Francisco Neugebauer, un ingeniero austríaco que tenía experiencia como pocos en el ramo de la electricidad. Neugebauer había llegado a México como delegado de la compañía Siemens \& Halske, tal vez alrededor de $1890 . .^{48}$ Sus credenciales las reconocía públicamente Schöndube: "El gran desarrollo que había tomado en los últimos años mi establecimiento recibirá un nuevo e importante impulso con la valiosa ayuda del Sr. D. Francisco Neugebauer", quien tenía -escribió- experiencia técnica

\footnotetext{
${ }^{44}$ Valerio, “Empresas, tranvías”. Ramos, El comercio eléctrico, p. 15.

${ }^{4}$ Puede verse MMOyB, Plano 2775-OYB-7233-A, "Plano del Lago de Chapala y Río Santiago", con indicación de concesiones otorgadas.

${ }_{46}$ AHMC, Actas de Cabildo, lib. 81, acta 8, fs. 10v.-14f, sesión del 15 de febrero de 1904.

${ }^{47}$ CEHM-CARSO, Col. José Yves Limantour, CDLIV.2a.1901.4.21476 y CDLIV.2a.1900.3.15277.

48 Rodríguez, "Gobierno local”, p. 187.
} 
demostrada en la dirección de grandes instalaciones de Europa y América del Sur, en la planta eléctrica de la Compañía Mexicana de Electricidad de la capital del país, y en su colaboración para la construcción de la hidroeléctrica de Necaxa, acreditando "sus aptitudes comerciales y administrativas". 49

En los nuevos socios se reunía el conocimiento profundo y la relación con las dos grandes empresas de productos eléctricos alemanas, la Siemens y la AEG; entendían los secretos del funcionamiento de la tecnología relacionada con la electricidad. Fuera de Siemens, Neugebauer ayudó a que aún en 1906 y 1907 la AEG tuviera las mayores ventas de productos eléctricos en México, un dominio que se fue diluyendo con la penetración de las estadounidenses General Electric y Westinghouse. ${ }^{50}$

La relación entre Schöndube y Neugebauer terminó en 1911, cuando éste regresó a Austria, su lugar de origen, quizá ahuyentado por el movimiento revolucionario. Schöndube cerró un año después la casa de comisiones, dejó su residencia en la ciudad de México y pasó buena parte de su tiempo en la hacienda La Esperanza, en Jalisco, la cual había adquirido en 1909. Desde ahí se mantuvo activo en varios y novedosos negocios, pero la época que interesa aquí fue la de 1906 a 1914 aproximadamente, cuando amplió sus intereses, convirtiéndose en contratista de servicios como la instalación de redes de agua, de drenaje y pavimentación. A veces los ejecutaba directamente (con la conducción de Neugebauer mientras lo tuvo de socio), pero otras actuando como especulador, o en relaciones de amistad, contubernio y proveeduría con la Compañía Bancaria de Fomento y Bienes Raíces y el Banco Central Mexicano.

En su papel de ejecutores directos debe subrayarse su diversificación y su capacidad para perseguir y conseguir contratos en varias ciudades del país, muchas distantes entre sí, con la

\footnotetext{
${ }^{49}$ CEHM-CARSO, Col. José Yves Limantour.

50 Liehr y Torres, “Formas y estrategias de expansión”, p. 205.
} 
experiencia que les habían dado sus ventas en el sector eléctrico por toda la República. Aún más, conviene recalcar que en el momento en que actuaron había nuevas posibilidades técnicas y avances a nivel económico que ponían empréstitos en la mesa de las administraciones municipales, "una tentación, un pecado y una solución (parcial) a sus problemas de financiamiento". ${ }^{51}$

Respecto a las obras de agua potable y drenaje, participaron al menos en Celaya, Querétaro y Oaxaca, y como intermediarios en Puebla y Aguascalientes. Según una carta que Neugebauer dirigió al ministro de Hacienda, José Yves Limantour, en diciembre de 1907, su empresa era representante en México de la fábrica alemana de tuberías Mannesmann, las cuales querían emplear en la distribución de aguas de la capital del país y habían empleado "en la distribución de aguas potables en Lagos [de Moreno], Durango, Celaya, Aguascalientes, totalmente, y en San Luis Potosí, Guadalajara, San Pedro de los Pinos y Colonia de la Huerta del Carmen, en esta capital, parcialmente". ${ }^{52}$ No está del todo claro su papel, si fueron vendedores de los productos a los municipios, si hicieron ellos mismos alguna instalación, o si fungieron como proveedores de la Bancaria u otra compañía encargada de su instalación; lo que es seguro que para entonces estaban de lleno en terrenos empresariales relacionados con el agua potable y es probable que hayan tenido los tres tipos de intervenciones a partir de su función principal de distribuidores de empresas alemanas.

En Celaya se valieron del contacto con el propietario alemán de una ferretería de esa ciudad, quien los habría puesto en comunicación con el Ayuntamiento en 1907. En diciembre firmaron un primer contrato para surtirle 2710 metros de tubería. Fue el inicio de una serie de ventas encaminadas a que Celaya contara con un servicio de distribución de agua en red, que dejara atrás

51 Rodríguez, La experiencia olvidada, p. 129.

52 CEHM-CARSO, Col. José Yves Limantour, CDLIV.2a.1908.22.139. 
el antiguo sistema, una pretensión compartida con muchas otras ciudades. En el caso, las obras incluían la construcción de un depósito, una torre de fierro para elevarlo, bombas para subir el agua y otros accesorios para distribuirla. Actuando como negociante, Neugebauer protocolizó varios acuerdos que involucraban pago de intereses (al parecer era un financiamiento directo, sin el concurso de un banco) y que sucesivamente se hicieron más gravosos para el municipio. ${ }^{53}$ Aunque se conocen menos detalles, los acuerdos debieron incluir la construcción, o al menos la proyección de una red de drenaje, como lo demuestra un plano que al efecto se elaboró en 1908. ${ }^{54}$

En la vecina ciudad de Querétaro siguieron un camino similar. El Ayuntamiento decidió en 1907 sustituir tuberías de barro por otras de fierro que al parecer fueron compradas a Schöndube y Neugebauer. Con sus buenos oficios de persuasión debieron convencer a las autoridades para dar un paso adelante, $\mathrm{y}$ a finales de 1909 las partes firmaron un contrato para la construcción de una infraestructura hidráulica completa. Se trató de una obra relativamente económica y de amplia cobertura. El costo total fue de 200000 , sin un crédito bancario de por medio, sino con ciertas ventajas para el municipio, pues las obras se pagarían a lo largo de 8 años, sólo a partir de su finalización, y con un interés anual de $8 \%$. La compañía entregó la nueva entubación en enero de 1911, con una extensión de 23768 metros lineales que permitían la conexión de 2131 instalaciones domiciliarias. Desde entonces el Ayuntamiento sufrió mes a mes para cubrir sus compromisos y no obtuvo la recaudación que había calculado por las mercedes particulares. ${ }^{55}$ Como en otros casos, cabe señalar, la nueva entubación supuso la supresión definitiva del antiguo acueducto elevado.

\footnotetext{
53 Puente y Soldara, “La bola de agua”.

54 AHUG, fondo Familia Ponciano Aguilar, plano 2: "Plano de la red de tubería del drenaje para la ciudad de Celaya, 28 de octubre de 1908”.

55 Gutiérrez, “Infraestructura hidráulica”, pp. 108-114.
} 
La misma compañía firmó en Oaxaca acuerdos, en diferentes condiciones, para empezar obras en $1910 .{ }^{56}$ Hacía varios años que la ciudad había hecho intentos para modernizar la distribución de agua, pues su cobertura era limitada y era muy difícil acceder a fuentes adicionales que proporcionaran las cantidades que requerían una red mayor y la operación de un sistema de drenaje. En ese escenario se presentaron Schöndube y Neugebauer, quienes se obligaron a ejecutar un proyecto que incluía la construcción de un tanque, la conducción de agua desde una fuente distante, y el tendido de la red de agua y drenaje. Para financiar las obras recurrieron esta vez a un banco alemán, el Banco Germánico de la América del Sur (capitalizado por el Dresdner Bank), que proporcionó al Ayuntamiento, teniendo como fiador al gobierno de Oaxaca, 1800000 pesos pagaderos en un largo plazo, de 50 años. De acuerdo con Juan Hugo Sánchez, en septiembre de 1911 en la red de agua se había avanzado una tercera parte y en la de drenaje sólo $25 \%$, pero el dinero se estaba agotando. ${ }^{57}$ Según Carlos Lira y Danivia Calderón, la Revolución dificultó el cumplimiento del contrato y después de muchos años, en 1927, la empresa de Schöndube dio por concluidas las obras, que sólo alcanzaron a cubrir, en el mejor de los casos, "las zonas que formaban parte de la mancha urbana porfiriana”. ${ }^{58}$

Su faceta de vendedores y de contratistas ilustra solo una parte de los procesos de expansión, en particular la de su presencia en distintas urbes. Pero Enrique Schöndube y su socio Francisco Neugebauer fueron, además de ejecutores de obras, agentes cazacontratos o, por decirlo mejor para efecto de este análisis,

56 Lizama, Zamora, pp. 357-359. El Economista Mexicano (3 dic. 1910), t. LI, núm. 10, p. 210. GAмвоA, “El financiamiento”, pp. 106-107. BirrichagA, “Las empresas”, pp. 206-207. LirA, “Obra y servicios”, pp. 242-243 y nota 67, p. 243.

57 Sánchez, “Gobierno municipal”, pp. 119-123.

58 Lira y Calderón, “De capital estatal a parque temático”, p. 261. 
funcionaron en ocasiones como eslabones de la cadena construida por el Banco Central Mexicano y la Compañía Bancaria para apoderarse de todos los servicios en varias ciudades.

La Compañía Bancaria de Obras y Bienes Raíces se organizó en 1905, aunque su historia debe buscarse en empresas e iniciativas que para entonces estaban en pleno funcionamiento. Cambió su denominación en 1909 por la de Compañía Bancaria de Fomento y Bienes Raíces (COBAFYBRA), aunque en una y otra etapa estuvo compuesta de tres departamentos, según lo sugiere su título, uno de "banco", otro de "obras" de construcción, y otro de "bienes raíces" ${ }^{59}$ El gran cerebro detrás de ella era Fernando Pimentel y Fagoaga, quien no sólo era un socio importante y aportó a su formación empresas en las que tenía una participación mayoritaria, sino que ponía su trabajo, su influencia pública, su desempeño en las instituciones de gobierno, su experiencia empresarial, sus intereses y sus vínculos internacionales.

La Bancaria nació como un proyecto alterno del Banco Central Mexicano (всм), que a su vez había sido fundado en 1899, у que desempeñó entre sus funciones principales la de "promover inversiones de un restringido grupo de empresarios en proyectos industriales y ligados a concesiones gubernamentales" ${ }^{60}$ Una parte importante del capital exhibido en la Bancaria y en el Central correspondía a inversionistas franceses a través de participaciones en bancos. Según su acta, en 1906 la Bancaria tenía 50000 acciones de 100 pesos cada una: $51 \%$ estaba en poder de tres bancos: $31 \%$ le correspondía al Central Mexicano, $10 \%$ al Banco Nacional de México y 10\% al Banco de Londres y México; $42 \%$ eran acciones liberadas, es decir, estaban representadas por tres compañías de las que Pimentel y Fagoaga era el principal inversionista: Compañía de Cemento Portland S. A.,

\footnotetext{
59 Paolo Riguzzi, “Sistema financiero”, p. 11. GамвоA, “El financiamiento”, p. 107.

60 Paolo Riguzzi, “Sistema financiero", p. 11.
} 
Compañía General de Pavimentación S. A., y Pimentel y Hermano. Hugo Scherer y Luis Barroso Arias tenían 3\% cada uno, y el 1\% restante se lo repartían con minúsculas participaciones algunos de los más importantes capitalistas de la época: Pablo Macedo, José Castellot Batalla, Francisco Rincón Gallardo, Luis G. Tornel y otros. ${ }^{61}$

El control accionista de los bancos remite al origen de buena parte del capital, inversiones francesas (en 1909 la Bancaria colocó después de su nombre, y entre paréntesis, Société Foncière du Mexique), y juntas representaban bien los alcances de las "altas finanzas", los mejores y últimos tiempos del estado liberal, y la regulación privada de la economía. Adicionalmente, los préstamos otorgados por el Central Mexicano y otros bancos, por ejemplo para el financiamiento de obras y servicios públicos, se capitalizaban por medio de la emisión de bonos, lo que ampliaba el alcance de los mecanismos de circulación, con el concurso de "capitalistas que en el extranjero se hallaban dispuestos a invertir en estos negocios que juzgaban redituables". ${ }^{62}$

Dos de las cabezas principales del Central Mexicano eran Enrique C. Creel y Joaquín Casasús. ${ }^{63}$ Fernando Pimentel y Fagoaga, que era heredero de una de las genealogías más largas y lustrosas del país, fue gerente y vicepresidente del BCM, presidente de la coBAFYBRA, y vicepresidente de la Compañía Fundidora de Fierro y Acero de Monterrey, entre otros cargos. Entre 1903 y 1911 fue presidente municipal de la ciudad de México, un ayuntamiento que por entonces estaba perdiendo capacidad de gobierno y que, según Rodríguez Kuri, era "políticamente inocuo, y 'colonizado' por los financieros del régimen”, encabezados desde luego por el propio Pimentel. ${ }^{64}$

${ }^{61}$ Sistematización propia a partir de los datos consignados por JiMÉNEZ, La traza del poder, pp. 96-97.

${ }^{62}$ GamboA, "El financiamiento", pp. 109-110.

63 Trentini, El florecimiento, segunda parte, pp. 5-16.

${ }^{64}$ Rodríguez Kuri, La experiencia olvidada, p. 68. 
Pablo Macedo González Saravia, por su parte, era abogado y miembro del Consejo de Administración del Banco Nacional de México, diputado federal en varias ocasiones, y cofundador de la mayor empresa productora de cobre en el porfiriato. ${ }^{65} \mathrm{Su}$ hermano Miguel fue también presidente del Ayuntamiento de la ciudad de México en un corto periodo (1898-1899) que, sin embargo, fue suficiente para favorecer desde ahí los negocios de Pablo, como el de la Compañía de Pavimentos y Adoquines de Asfalto, que "monopolizó los contratos de pavimentación del ayuntamiento". ${ }^{66}$

La importancia de la Compañía Bancaria quizá sólo la han atisbado unos cuantos autores, pero hasta ahora no se ha atendido en toda su dimensión. Jorge H. Jiménez ha documentado muchos detalles de su constitución y de sus intereses en los bienes raíces de la ciudad de México y en la producción de cemento. ${ }^{67}$ Leticia Gamboa explicó con inteligencia los entretelones financieros y sus intervenciones como contratista de obras de agua, drenaje y pavimentación en Puebla. ${ }^{68}$ Otros han descrito su participación en varias ciudades, pero sin establecer las conexiones que había ni la relación con el negocio de la electricidad, que manejaron a gran escala pero por medio del Banco Central Mexicano. Sólo uniendo innumerables piezas el conjunto adquiere sentido: las empresas hermanas que unía Pimentel y Fagoaga alcanzaron una enorme notoriedad en el sector inmobiliario de la ciudad de México (en menor medida en Guadalajara), en la producción de cementos, en la construcción de mercados, escuelas y edificios públicos, en la generación de electricidad, en los servicios de agua, drenaje, pavimentación, alumbrado, tranvías y teléfonos para muchas ciudades del país.

\footnotetext{
65 Ludlow, “La formación”, p. 146.

66 Jiménez, La traza del poder, p. 101.

67 Jiménez, La traza del poder, pp. 97-98, 115-116 y otras.

68 Gambо,, “El financiamiento”, pp. 99-113.
} 
Algunos de los pasos de concentración de la Bancaria y el Central Mexicano estuvieron acompañados por Schöndube y Neugebauer. Lo ocurrido en Puebla y en Aguascalientes (junto con el caso de Guadalajara, en buena medida de Morelia y otras) documenta con especial elocuencia los mecanismos seguidos hacia instituciones más sofisticadas.

En Puebla, el Ayuntamiento decidió hacia 1905 un ambicioso programa de construcción de obras y servicios públicos que debían cubrir la provisión de agua, el drenaje y la pavimentación de calles. Entre las seis propuestas que originalmente recibió, una correspondía a la sociedad Pearson \& Son (de la que se trata más adelante), otra a la compañía pavimentadora Neuchâtel Asphalt Paving, y una más, que resultó ganadora, a H. Tron, Ibáñez, Prieto y Compañía, detrás de la que estaban los intereses del grupo que unos meses después constituiría la Compañía Bancaria. En 1906 el Ayuntamiento negoció con el Banco Oriental de México, una institución regional, un préstamo modesto, de 100000 pesos, a un rédito "elevadísimo" pagadero en el mínimo plazo de un año. En busca de mejores condiciones, negociaron con el Central Mexicano un empréstito, mediante una emisión de bonos con un interés de 5\% anual, de 3.6 millones. En 1908 se ampliaron los proyectos y entonces se presentaron Schöndube y Neugebauer y la Bancaria para la construcción de obras de agua potable. Todo indica que Schöndube estaba en contubernio con la Bancaria, que presentó su propio proyecto y resultó ganadora. ${ }^{69}$

Carlos Contreras y Jesús Pacheco apuntaron que "muy poco faltó" para que la Bancaria fuera la contratista exclusiva de todos los trabajos emprendidos en Puebla por el presidente municipal Francisco de Velasco. ${ }^{70}$ En realidad lo fue. Una excepción hallada por estos autores era el contrato adjudicado a Lister y García Teruel para pavimentar algunas calles, aunque uno y otro tenían,

69 Gamboa, “El financiamiento”, pp. 106-107.

70 Contreras y Pacheco, “De la modernización porfiriana”, p. 187. 
al menos, acuerdos y negocios con la Bancaria. Otra, el similar contrato entregado a la Compañía Mexicana de Pavimentos de Asfalto y Construcciones S. A., del magnate petrolero Edward Doheny; ésta, no obstante, y según se aseguró en un informe de la Bancaria, tenía "celebrados arreglos con nuestra compañía para la ejecución de sus obras, así como en lo que se respecta a sus utilidades". ${ }^{71}$

Como se ha mostrado con mucho detalle en otra parte, ${ }^{72}$ en el proceso para que Aguascalientes pasara de una red modesta de agua potable a una de mayores alcances, una pieza clave fue el presbítero Ramón Gutiérrez, un oscuro personaje local que ayudó a tejer las relaciones entre intermediarios, especuladores, abogados, representantes, diputados locales, el gobierno del estado y el presidente de la República. Su primera conexión debió ser con Schöndube y Neugebauer, a quienes en 1906 traspasó oficialmente una concesión obtenida previamente para aprovechar las aguas del río Morcinique, construir ahí una presa y tender la red de distribución a la ciudad.

En 1906, un "suntuoso banquete" reunió en Aguascalientes al gobernador, a la élite local y a Francisco Neugebauer, quien acompañado de su esposa selló lo que la prensa llamó el “initium de una empresa". ${ }^{73}$ En 1909 se habían formado planos, elaborado estudios y avivado polémicas. Entre contingencias y tropiezos, la compañía alteró en dos sentidos muy importantes las condiciones iniciales: su primera concesión -en la que arriesgaba su capital- se transformó en un contrato; además, trasladó sus obligaciones y derechos a la Compañía Bancaria, dejándole el terreno libre, seguramente en una decisión negociada previamente, y estipulando que el gobierno debía financiar los trabajos con un empréstito del Banco Central Mexicano.

${ }_{11}$ El Economista Mexicano (13 mayo 1911), t. LII, núm. 7, pp. 145-147.

72 Para una historia detallada puede verse Martínez, Cambio y proyecto urbano, pp. 167-196.

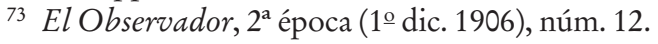


En 1910 se protocolizaron dos nuevos convenios con el apoderado de la Compañía Bancaria y del Banco Central Mexicano, que revelan las irregularidades y presiones económicas y políticas que había detrás de este tipo de trabajos. ${ }^{74}$ Las obras de Aguascalientes se valuaron en 400000 pesos, pero el préstamo al que se obligó el gobierno del estado mediante la emisión de bonos era de 1.3 millones, siendo la diferencia una abultada cuenta de comisiones, indemnizaciones injustificadas, "gastos de promoción, etc." ${ }^{75}$ Un procedimiento tan poco pulcro, donde no medió un concurso para la ejecución ni el gobierno tuvo opción para elegir la contratación del empréstito ${ }^{76}$ involucró a muchos actores, funcionarios que, como se ha mostrado en otras partes, solían recibir sobornos. ${ }^{77}$ En el caso que nos ocupa, la propia Bancaria gestionó la contratación de un segundo empréstito por una cantidad similar (un millón de pesos) para financiar la pavimentación y el saneamiento de la ciudad, en unos contratos que nunca fueron públicos ni aprobados por el Congreso, como por ley debían serlo. ${ }^{78}$

En procesos paralelos al de su penetración como contratista de los trabajos de pavimentación, drenaje e introducción de la red de agua, la Compañía Bancaria de Fomento y Bienes Raíces cerró el círculo, involucrándose en Aguascalientes en la concesión del servicio de energía eléctrica al menos de dos maneras. Por una parte, y valiéndose de personajes como León Signoret, José Sariñaga, Hugo Scherer y el propio Neugebauer, empezaron en 1905 a adquirir acciones de las dos compañías

\footnotetext{
${ }^{74}$ Los contratos fueron publicados en El Republicano (17 jul. 1910), pp. 1-6. 75 AHEA, SG, c. 11, 1905, 11.4.

${ }^{76}$ Sobre este proceso de gestión de préstamos véase ConNolly, El contratista, p. 132.

77 Véase al respecto Connolly, El contratista. “Aguascalientes”, en Temis, 5 (24 sep. 1910). “Aguascalientes”, en Temis, 2 (3 sep. 1910).

78 El Republicano (17 jul. 1910), pp. 3-6.
} 
locales de electricidad, hasta que en marzo de 1911 tomaron el control y las fusionaron. ${ }^{79}$

Muchos trabajos realizados en torno a empresas similares por toda América y Europa han evidenciado los mecanismos idénticos utilizados por los inversionistas para controlar empresas locales y unirlas a su red: iniciar con una participación accionaria en las compañías existentes o crear una pequeña como competidora, luego hacer fuertes inversiones en la generación de electricidad capaces de cubrir varias poblaciones y necesidades (mineras, industriales, de transporte, etc.), ahogar a las rivales, comprarlas e imponer un monopolio, todo mientras se apoyaban en agentes, abogados y políticos que desbrozaban el camino. ${ }^{80}$

Con el control de las dos empresas que producían la energía eléctrica para el transporte y la iluminación pública y domiciliaria en Aguascalientes, la Bancaria obtuvo un contrato diferente para vender energía eléctrica, esta vez a todo el estado, a partir de una de sus compañías hermanas, la Compañía Hidroeléctrica e Irrigadora de Chapala. El convenio, que tampoco estuvo exento de irregularidades, se firmó el 4 de diciembre de 1909, es decir, tres meses antes que los correspondientes a los trabajos de agua potable y los compromisos para ejecutar las obras de drenaje y pavimentación..$^{81}$ En unos cuantos pero enredados pasos la Bancaria se hizo de todos los contratos - con grandes ventajas económicas- para construir sistemas de agua, drenaje y pavimentación en Aguascalientes (igual que en Puebla), y engulló

\footnotetext{
79 Martínez, Cambio y proyecto urbano, pp. 173-176.

${ }^{80}$ Véase Horacio Capel, "Innovación técnica, gestión empresarial y financiación en el capitalismo global de comienzos del siglo xx. Los casos de Brazilian Traction y Barcelona Traction", Introducción al Simposio Internacional "Globalización, innovación y construcción de redes técnicas urbanas en América y Europa, 1890-1930", Universidad de Barcelona, enero de 2012, 36 pp. [en línea] http://www.ub.edu/geocrit/cCapel_Innovacion_intro.pdf [27 de enero de 2015], pp. 14-15.

${ }^{81}$ Martínez, Cambio y proyecto urbano, pp. 185-186.
} 
además a las empresas de electricidad para ponerlas en otra de sus áreas privilegiadas de interés.

Un eslabón más. La historia de la Compañía Hidroeléctrica e Irrigadora de Chapala conduce a Guadalajara y a la historia del veloz proceso por el que aquí, como en otros lados, los intereses de un gran grupo empresarial (el Banco Central Mexicano) pudieron apoderarse de todo un sector de servicios, penetrando en las inversiones locales que hasta poco tiempo atrás los habían ofrecido parcialmente. Desde 1892 y hasta la irrupción del Central Mexicano, la producción de energía eléctrica en Guadalajara estuvo dominada por empresarios de origen español y por barcelonnettes cuyas inversiones principales habían estado en el comercio de ropa y en la industria textil. ${ }^{82}$ Fue natural su interés en generar energía para sus fábricas y en electrificar los tranvías que condujeran a sus trabajadores. Por un tiempo, otro protagonista en Guadalajara fue Enrique Schöndube, quien obtuvo hacia 1897 una concesión en el río Santiago, inmediato a Guadalajara y que en diversos puntos ofrecía la posibilidad de aprovechar sus aguas en la generación eléctrica. Schöndube formó la Empresa de Luz y Fuerza Eléctrica de Las Juntas y en 1902 habría hecho un gran negocio al obtener, según indica una fuente, 190000 pesos de la Compañía Industrial de Guadalajara, detrás de la que estaban inversionistas barcelonettes, por las instalaciones de Las Juntas y la concesión para el uso de las aguas. ${ }^{83}$

Lo que hizo el Banco Central Mexicano fue constituir en la ciudad de México la empresa Electra en 1903, comprar la Compañía de Tranvías de Guadalajara (del empresario local Francisco Martínez Negrete Alba), comprar después la Compañía de Luz Eléctrica de Guadalajara (cuyo inversionista principal era José María Bermejillo, español y cuñado de Martínez Negrete),

\footnotetext{
82 Véase Lizama, “Francisco Martínez Negrete". Valerio, Los barcelonnettes. 83 Valerio, Los barcelonnettes, p. 260.
} 
hacerse del departamento eléctrico de la Compañía Industrial de Guadalajara en 1907, hasta cambiar su nombre y convertirse en la Compañía Hidroeléctrica e Irrigadora de Chapala S. A. hacia 1909. Del total de sus acciones, $78 \%$ correspondían al вСм, cerca de 5\% eran de Pimentel y Fagoaga y el resto se dividía entre otros empresarios cercanos al mismo círculo. ${ }^{84}$

En 1910, la Compañía Hidroeléctrica e Irrigadora de Chapala se había hecho del control de las cuatro grandes plantas hidroeléctricas en la zona de Guadalajara, sobre el río Santiago, que habían sido construidas en los años previos por Bermejillo, Schöndube y otros: El Salto, Las Juntas, Puente Grande y La Experiencia, que en conjunto producían 35000 caballos de fuerza anualmente. Con esta producción se suministraban alrededor de 20000 caballos de fuerza a los servicios de alumbrado y tranvías de Guadalajara, así como a muchas de las industrias de esa ciudad, en varias de las cuales tenían intereses los mismos accionistas. De este modo, quedaban 15000 caballos de fuerza que era necesario ofrecer, lo que explica con facilidad el interés en Aguascalientes, Zacatecas y San Luis Potosí, donde según un periódico nacional la compañía ya había firmado contratos para distribuir energía en enero de 1910.85

En materia eléctrica los intereses del Banco Central Mexicano adquirieron dominio en una región importante que cubría al menos los estados recién citados y el de Jalisco, con su centro productivo anclado en la energía hidráulica de los alrededores de Guadalajara, la segunda ciudad en población del país. Desde ahí disputaron otros terrenos, por ejemplo los vecinos de Guanajuato y Michoacán, que para entonces había ganado la Guanajuato Power and Electric Company. ${ }^{86}$

\footnotetext{
84 VAlerio, “Empresas, tranvías”, pp. 3-21.

85 El Economista Mexicano (15 ene. 1910), p. 9.

86 Véase, por ejemplo, LiEHr y Torres, "Las compañías eléctricas extranjeras", p. 29.
} 
Como quiera, Guadalajara fue para la Bancaria también un centro de expansión en otro sentido: el negocio inmobiliario. En el Distrito Federal era uno de sus principales negocios y participó en algunas de las colonias más relevantes construidas por entonces. ${ }^{87}$ A principios de 1907, ante un notario de la ciudad de México, se constituyó la Compañía de Obras y Bienes Raíces de Guadalajara; si su nombre no revelara su hermandad, lo hacen los integrantes de su consejo: Fernando Pimentel y Fagoaga como presidente, Luis G. Tornel y Leandro F. Payró. Su objeto fue "urbanizar, fraccionar y vender la colonia Moderna". ${ }^{88}$

Si en el sector eléctrico la Bancaria y el всм articularon estrategias para dominar una región importante, en el campo de la pavimentación y la fabricación de cemento la Bancaria se convirtió en un actor privilegiado del país, siguiendo procedimientos similares de absorción. Cuando en 1889 Pablo Macedo, Leandro F. Payró, Luis García Teruel Manso (suegro de Payró) y otros formaron la Compañía de Pavimentos de Adoquines de Asfalto Comprimido, otras cinco o seis empresas tenían mayor presencia y mejores contratos para pavimentar calles. ${ }^{89}$ Desde ahí su ascenso fue rápido. Entre 1891 y 1900 esta compañía fue la contratista principal del Ayuntamiento de la ciudad de México. A partir de 1899 el ayuntamiento otorgó nuevos contratos que recayeron sobre la Neuchâtel Asphalt Paving Company Limited, y sobre The Barber Asphalt Paving Company. La primera, de capital suizo, se mantuvo, pero la segunda delegó sus obligaciones a la Compañía de Pavimentos de Adoquines y Asfalto, en uno de los pasos seguidos por Fernando Pimentel y Fagoaga y su grupo de accionistas, quienes absorbieron ambas para formar

87 Jiménez, La traza del poder, pp. 139-140.

88 Hernández, Guadalajara, p. 130. En 1910 se formalizó la Compañía de Fomento y Bienes Raíces de Guadalajara, que no habría que confundir, pues en esta su accionista principal (81.6\%) era el Banco de Jalisco. VALERIo, Los barcelonnettes, pp. 286-289.

89 Jiménez, La traza del poder, pp. 87-91. 
en 1905 la Compañía General de Pavimentación S. A. Los mismos intereses habían creado en 1900 la Compañía Mexicana de Cemento Portland S. A., con la cual fueron cerrando el círculo hacia un dominio mayor en un negocio que por entonces vivía sus primeros años. ${ }^{90}$

Además de los casos expuestos hay otros menos conocidos y seguramente varios desconocidos de contratos por los que la Bancaria proyectó y ejecutó trabajos de construcción de obras de saneamiento, agua potable y pavimentación. Lo hizo al menos en la ciudad de México, en Zamora, Morelia, Veracruz, Chihuahua, Ciudad Juárez y Durango. ${ }^{91}$ En septiembre de 1908 Luis Fernández Castelló y Leandro Payró se estaban moviendo entre presidentes municipales, gobernadores y ministros con el deseo de que la Bancaria fuera la contratista de "la urbanización y saneamiento de las ciudades fronterizas de Laredo, Ciudad Juárez y Ciudad Porfirio Díaz (hoy Piedras Negras)", aunque no está claro si lo consiguieron. ${ }^{92} \mathrm{El}$ informe que se les presentó a sus accionistas en 1911 celebraba "un ensanche satisfactorio en los negocios que corresponden a los departamentos bancario y de obras”, un aumento en la venta de terrenos rústicos y urbanos, y, en general, una “mayor solidez de la compañía”. ${ }^{93}$

En Puebla, además de todo lo mencionado, la Compañía Bancaria emprendió la construcción del mercado La Victoria,

90 López, Los servicios públicos, p. 191. Jiménez, La traza del poder, pp. 115116. El Mundo Ilustrado (27 feb. 1910), pp. 32-33.

91 Los casos están estudiados o referidos en Lizama, Zamora. Connolly, El contratista. URIBe, Morelia: los pasos. GamboA, "El financiamiento". El Economista Mexicano (13 mayo 1911), t. LII, núm. 7, pp. 145-147. AHDF, Planoteca, Planos y proyectos, 1861-1983, c. 100, exp. 6, Planos del proyecto de saneamiento para Ciudad Juárez Chihuahua. Compañía Bancaria de Fomento y Bienes Raíces de México.

92 CEHM-CARSO, Col. José Yves Limantour, CDLIV. 2a. 1908. 29. 88.

93 El Economista Mexicano (29 abr. 1911), t. LII, núm. 5, pp. 99-100. El Economista Mexicano (13 mayo 1911), t. LII, núm. 7, pp. 145-147. 
que costó “algo más de un millón de pesos”, una suma realmente importante en la época. ${ }^{94}$ También en Morelia construyó un mercado moderno, el San Francisco, siguiendo el modelo del mercado Martínez de la Torre, que posiblemente construyó la misma compañía en la colonia Guerrero de la ciudad de México. El Mundo Ilustrado celebraba en febrero de 1910 que el gobernador de Michoacán hubiera elegido a la Bancaria para realizar todas las obras necesarias para una amplia y moderna red de agua, “pues esta compañía cuenta con un departamento de ingeniería civil capaz de responder a todas las exigencias de las ciudades modernas". ${ }^{95}$ En agosto de 1909 la Bancaria entregó a la Secretaría de Instrucción Pública y Bellas Artes una escuela "de primera clase", que formaba parte de un ambicioso plan de construcción, ${ }^{96}$ y por todo el país trató u obtuvo contratos en muy favorables condiciones para sus inversionistas.

Schöndube, por su parte, mantuvo durante años un dinamismo empresarial que le permitió seguir ampliando sus intereses y presencia en diversas regiones del país, a veces relacionado con otras compañías como la Bancaria y la Pearson, otras como competidor. Parece que en Querétaro, Torreón y Zacatecas ganó los contratos para construir centrales eléctricas, ${ }^{97}$ y en Durango consiguió una concesión -que quizá no hizo válidapara generar, trasmitir y ministrar energía a partir de unas caídas de agua. ${ }^{98}$ En 1910 intentó competir en Mérida, obteniendo una concesión para abrir una planta eléctrica, y negoció también una concesión para el servicio eléctrico en Tampico. En marzo de 1912, después de varios intentos, el cabildo de Colima le dio luz verde para que le ofreciera el servicio de alumbrado público,

\footnotetext{
94 Gaмво,, "El financiamiento", p. 118.

95 El Mundo Ilustrado (27 feb. 1910), pp. 32-33.

96 CEHM-CARSO, Col. José Yves Limantour, CDLIV. 2a. 1908. 13. 96 y CDLIV. 2a. 1909. 2. 86.

97 Lienr y Torres, “Formas y estrategias de expansión”, pp. 211-214.

98 El Economista Mexicano, tomo LI, núm. 10 (3 dic. 1910), p. 210.
} 
un negocio que fue ampliando con la constitución, en 1914, de la Compañía Hidroeléctrica Occidental. ${ }^{99}$ Como se ve, sus intereses se extendían lo mismo por el Norte que por el Centro, el Pacífico, el Golfo y la Península de Yucatán.

CAPITALISMO ORGANIZADO: CONCENTRACIÓN EMPRESARIAL

EN LA RUTA DE UNA COMPETENCIA MONOPOLÍSTICA PARA SERVICIOS PÚBLICOS URBANOS

Desde el punto de vista empresarial, los negocios de Schöndube $\&$ Neugebauer eran amplios y diversificados, ya como distribuidores de materiales y equipo, ya como contratistas, a veces respaldados con financiamientos bancarios. El carácter de la Compañía Bancaria era el de una sociedad anónima asentada en México, capitalizada con acciones en manos de los tres grandes bancos del país, principalmente el Central, pero refaccionada con capitales foráneos a través de la venta de bonos en el extranjero. Ambas participaron en diferentes grados en muchas ciudades mexicanas, pero no fuera del país, y constituyeron una alianza entre bancos y constructores que debe remarcarse. Tanto la sociedad del inglés Weetman Pearson, como la Mexican Light and Power Company (MLPC, cuya figura central fue Frederick Pearson, estadounidense sin ningún vínculo familiar con Weetman), fueron, en cambio, dos buenos ejemplos del estadio mayor de los negocios, ya como "grupo de inversión internacional" -en el primer caso-, ya como FSC extendidas en sus intereses y áreas de influencia, o como trasnacionales que tocaban con sus tentáculos a varios, a veces muchos, países. La MLPC era un holding especializado en energía eléctrica, cuya estructura de capital se basaba en la emisión de deuda en los mercados europeos.

99 AHMC, Actas de Cabildo, lib. 85, acta 14, fs. 31f-33f, sesión del 27 de marzo de 1912. Preciado, "Los cristeros", p. 86. 
Desde la teoría económica, vale la pena ubicar a Weetman Person y a la Mexican Light and Power Company, pero también a la Bancaria, como expresiones de un "capitalismo organizado" o "capitalismo corporativo". Poco importa el nombre, escribió Eric Hobsbawm, "la concentración avanzó a expensas de la competencia de mercado, las corporaciones a expensas de las empresas privadas, los grandes negocios y grandes empresas a expensas de las más pequeñas”, y “esa concentración implicó una tendencia hacia el oligopolio". ${ }^{100}$ Puede que el nombre sí importe, porque estando claro que en el contexto empresarial y tecnológico de la época se produjo una competencia imperfecta en los distintos servicios públicos, debe caracterizarse más como una competencia monopolística que como un oligopolio. Había en el horizonte diferencias y calidades entre las obras a realizar: los tranvías podían ser de tracción eléctrica o animal; las calles podían cubrirse de asfalto, empedrarse o sólo aplanarse; las redes de agua podían construirse con muchas variantes; la electricidad podía producirse a baja escala, con vapor, o en grandes dimensiones, con caídas de agua. Las ciudades tenían ciertas opciones, pero todas circunscritas en un medio de pocas empresas, que tendían a ser menos cada vez, y que se apoyaban en redes de influencias y de presión con las cuales podían imponer precios y condiciones más allá de las reglas de la oferta y la demanda.

Weetman Pearson, el magnate cuya trayectoria en México han estudiado a detalle Priscilla Connolly y Paul Garner, obtuvo ganancias monumentales al amparo de Porfirio Díaz, principalmente por el contrato con el que construyó las obras del Gran Canal del Desagüe de la capital del país, pero también por su participación en negocios de ramos muy variados, como la misma producción de energía eléctrica, la construcción de obras de agua y saneamiento, la minería, los ferrocarriles, la explotación

100 Hobsbawm, La era del imperio, p. 52. 
de petróleo y otras muchas industrias. Los contratos de este solo empresario "absorbieron por lo menos la tercera parte de la inversión financiada con deuda pública de 1890 a 1911”.101

Connolly y Garner coinciden en que fueron sus obras en el Gran Canal del Desagüe de México las que catapultaron su carrera, a pesar de que para entonces había sido ya "un exitoso contratista de obras públicas en la Gran Bretaña victoriana”, y que había hecho trabajos importantes en Estados Unidos. ${ }^{102}$ Entre 1880 y 1920, agrega Garner, "la firma completó en todo el mundo más de 80 contratos de ingeniería". Realizó instalaciones ferroviarias y portuarias en Irlanda, España, Chile, Brasil y Colombia. Desde su núcleo petrolero de México, la compañía petrolera El Águila, Pearson y su hijo Clive establecieron oficinas y depósitos "en Nueva York, Guatemala, Belice, Río de Janeiro, Santos, Buenos Aires, Canadá, Uruguay, Paraguay y Chile", que controlaban desde sus oficinas centrales en Londres. Obtuvo también concesiones en Austria, Francia, Argelia, Marruecos, Túnez, Baluchistán (región en la actual Pakistán) y Sajalín (en Siberia). ${ }^{103}$

La información conocida sobre los intereses de Pearson en servicios públicos es superficial, con pocos detalles, pero indicativa. Garner, que se enfocó en sus contratos más espectaculares y en su compañía petrolera El Águila, apenas dejó algunas notas marginales sobre otros negocios. En ellas, sin embargo, se descubre que las obras de construcción de sistemas urbanos de drenaje, agua potable y pavimentación ocuparon siempre un lugar en su agenda de trabajo. En 1882, por ejemplo, había construido "un desagüe de aguas de torrente en Deptford, en el sureste de Londres", dos años después se encargó del "alcantarillado principal de Sheffield”, y aún en 1913 envió “una misión

101 Connolly, El contratista, p. 132.

102 GARNer, Leones británicos, p. 19.

103 Garner, Leones británicos, pp. 79, 283 y 291. 
para negociar" contratos "de obras públicas con los gobiernos de Colombia, Ecuador y Costa Rica” ${ }^{104}$

En México, lo que sabemos de su participación en servicios públicos es principalmente por Priscilla Connolly, pero también por autoras como Alma Parra. ${ }^{105}$ Las redes de agua y drenaje las tendió fundamentalmente en los puertos en que trabajó, como Veracruz, Coatzacoalcos, Salina Cruz y Mazatlán, y la producción eléctrica la desarrolló por medio de sus empresas en Tampico, Puebla, Veracruz, Orizaba y Córdoba. ${ }^{106}$ Es cierto que, como dice la autora, sus inversiones en electricidad "en ningún momento representaron los intereses principales de Pearson en México", sino que derivaron de su participación accionaria en minas y en una fábrica de yute en Orizaba. Con todo, "Pearson expandió su empresa en el ramo de la industria eléctrica, para llegar a controlar el sector en toda la región centro oeste de México [sic], para finales de la primera década del siglo [xx]", 107 lo que lo puso como uno de los actores principales en el proceso de concentración empresarial de la electricidad, al dominar los importantes estados de Veracruz y Puebla.

Su procedimiento fue rápido. Inició casi de forma accidental: adquirió la compañía de tranvías en Veracruz “porque, después de completar las obras portuarias, el presidente le pidió que se encargara de la electrificación del sistema”, y al tiempo compró la compañía de luz. Como en muchos casos que se han citado líneas arriba, aquí Pearson integró las dos empresas formando una nueva, la Vera Cruz Electric Light, Power and Traction Co. Ltd., escriturada en Londres. Al hacerlo, estaba formando una FSC, asociado con el ingeniero canadiense A. E. Worswick. "Pearson compró las concesiones eléctricas en Puebla en 1904, para formar la Puebla Tramway, Light and Power Company, y

\footnotetext{
104 GARner, Leones británicos, pp. 76-77 y 288-289.

105 PArra, “Lord Cowdray”, pp. 107-144.

106 Connolly, El contratista, pp. 18, 38-44 y 94-95.

107 Connolly, El contratista, p. 375.
} 
después repitió el proceso en Tampico, Orizaba y Córdoba. En total fueron ocho las compañías así constituidas”. ${ }^{108}$

Garner, lo mismo que Connolly, han subrayado la función de Pearson como contratista, aunque ambos admiten que " $m u$ chas compañías subsidiarias de Pearson que se desarrollaron como consecuencia de sus contratos de obras públicas, como sus inversiones en ferrocarriles, minas, servicios públicos y tierras", tuvieron un carácter diferente, de FSC, a lo que se agrega su carácter de comprador de pequeñas empresas hasta convertirse en un actor dominante en el servicio de electricidad y tranvías en la región de Puebla, Veracruz y parte de Tamaulipas, lo que claramente matiza su caracterización sólo como contratista. Así, el carácter empresarial de Pearson fue variado y complejo, difícil de enmarcar en estrechas clasificaciones conceptuales. Como han mostrado Bud Frierman, Godley y Wale, desde 1908 la organización administrativa de Pearson se hizo más sofisticada e intrincada: la Mexican Eagle Oil Company fue registrada en México, pero otras tres empresas se fundaron en Londres; sus negocios se agrupaban en docenas de firmas separadas, algunas cotizaban en la bolsa de valores de Londres, otras no. ${ }^{109}$

Su participación en los trabajos de saneamiento y agua en Veracruz, Coatzacoalcos, Mazatlán y Tampico siguieron una ruta similar a la de Schöndube y la Bancaria en otras partes, es decir, por medio de la contratación de empréstitos, con la emisión de bonos por parte de los gobiernos estatales. Si la empresa de Pearson figuraba en estos casos sólo por su relación con sus obras portuarias no es suficiente para perder de vista su participación en el negocio de servicios públicos. Sus negocios eran tan amplios que éste pasa desapercibido, pero era tal, que cuando en 1909 Fernando Pimentel, en su calidad de gerente del Banco

108 Connolly, El contratista, p. 376. Según Liehr y Torres, Pearson sólo tuvo algunas acciones a partir de 1906 y "al parecer logró el control total hacia 1922”; LieHr y Torres, “Las compañías eléctricas extranjeras”, p. 29.

109 Bud Frierman, Godley, Wale, “Weetman Pearson”, pp. 278 y 288. 
Central Mexicano y la Bancaria, se dirigió al ministro de Hacienda para pedirle su ayuda en la obtención de un contrato, no dejó de anotar que la suya, la Bancaria, "siempre que ha entrado en competencia con los señores S. Pearson and Son, Limited, y con otros contratistas", daba mejores garantías y precios. ${ }^{110}$

En 1909 Pearson fue contratado por la Mexican Northern Power Co. para construir una presa y planta hidroeléctrica sobre el río Conchos, en Chihuahua. El destino de las obras era ambicioso: por una parte buscaba abastecer las zonas mineras de Chihuahua, Coahuila y Durango, principalmente Parral, Santa Eulalia y Mapimí, por otra irrigar los campos de la región, y además surtir a los centros urbanos. ${ }^{111}$ La Mexican Northern Power Co. era una de las muchas empresas formadas al calor del éxito que por entonces vivía el sector eléctrico y este negocio ejemplifica bien la forma en que los pequeños, medianos y grandes empresarios fueron tomando parte en las oportunidades rentables. Entre 1906 y 1907 la Compañía Schöndube y Neugebauer -que se ha caracterizado con amplitud y que, como se ve, aparece una y otra vez en estas historias- obtuvo y modificó con el gobierno federal un contrato para aprovechar, como fuerza motriz, las aguas del río Conchos, construyendo una presa en el punto denominado "El Salto". ${ }^{112}$ Es posible que Schöndube y Neugebauer hayan negociado el traspaso de la concesión a la Mexican Northern Power Co., o que ésta haya obtenido un contrato similar para aprovechar las aguas en un punto inmediato. Lo cierto es que la intención de Schöndube y la construcción efectiva de la Mexican revelan el olfato que estos empresarios tenían para identificar los lugares y las posibilidades

110 CEHM-CARSO, Col. José Yves Limantour, CDLIV. 2a. 1909. 9. 53 b.

111 El Economista Mexicano (19 feb. 1910), p. 5. Coll-Hurtado y SÁnchez, “Minería y electricidad", pp. 198 y 201. Domínguez, La política de reforma agraria. Connolly, El contratista, p. 42.

112 Diario Oficial de la Federación (2 sep. 1907), Decreto núm. 432. Diario Oficial de la Federación (7 sep. 1907). 
de explotación en el territorio mexicano, y el encadenamiento que se daba entre unos y otros. Pearson, que tenía sus propios negocios de generación eléctrica, se limitó aquí a construir las obras, que concluyó en 1915. La Mexican, por lo demás, era una FSC de inversores canadienses de Montreal, Toronto y Ontario y fue adquirida poco después por la American and Foreing Power Co. ${ }^{113}$

El tercer gran conglomerado dominante en la contratación y prestación de servicios públicos en México al iniciar el siglo xx fue la Mexican Light and Power Company. A diferencia de las otras dos (Bancaria y Pearson), ésta se concentró preferentemente en la generación y aprovechamiento de energía eléctrica, aunque esto era sólo aparente, pues con ello las empresas abrían un abanico muy amplio de intereses en alumbrado, transporte y minas que a veces las convertía en monopolistas de estos servicios, pero también del bombeo de agua para el servicio domiciliario, algo que con frecuencia se pierde de vista.

El arquitecto de la Mexican Light and Power Company fue el estadounidense Frederick Pearson, un ingeniero eléctrico que en 1889 dirigió la electrificación de los tranvías de Boston, se enlazó en provechosas asociaciones con empresarios canadienses hacia 1893, y en 1899 fundó -con William Mckenzie y James Ross- la São Paulo Tramway, Light and Power Company, el gran modelo que aplicaron después en México y Barcelona, consistente en grandes hidroeléctricas que generaban energía a bajo costo, lo que conducía a ahogar a sus competidores y alcanzar monopolios al menos regionales. ${ }^{114}$

113 Wilkins, Hausman, Neles, Hertner y Lanthier, “Every city”, p. 114. Connolly, El contratista, p. 42.

114 Horacio Capel, "Innovación técnica, gestión empresarial y financiación en el capitalismo global de comienzos del siglo xx. Los casos de Brazilian Traction y Barcelona Traction”, Introducción al Simposio Internacional “Globalización, innovación y construcción de redes técnicas urbanas en América y Europa, 1890-1930", Universidad de Barcelona, enero de 2012, 36 pp. [en 
Autores escrupulosos, desde Luis Nicolau D’Olwer hasta la fecha, han llegado a confundir la figura de Weetman Pearson con la de Frederick Pearson y a asignar a uno los negocios del otro. ${ }^{115}$ Ciertamente, explicar los de Frederick y la Mexican Light and Power Company es complicado, y entre las múltiples investigaciones que hacen alusión a ellos, por su papel central en el sistema de alumbrado de la ciudad de México, se encuentran siempre versiones encontradas con las que hay que hilar fino. ${ }^{116}$

El papel protagónico en esta historia corresponde a la capital del país y su área circundante. Por muchos años, una de las empresas centrales en el sector de la energía eléctrica en la ciudad de México fue la Compañía Mexicana de Gas y Luz Eléctrica (Mexican Gas and Electric Company). Su antecedente se encuentra en 1865, con la formación de la Compañía Imperial de Gas, de capitales mexicanos y británicos, que fue adquirida en la década de 1870 por el inglés Anthony Gibbs \& Co ${ }^{117}$ Como revelan sus nombres, estas compañías transitaron de la iluminación de gas a la eléctrica. En 1882 se sumó, con dinero mexicano, la Compañía Limitada de Ferrocarriles del Distrito, dedicada al servicio de tranvías, movidos aún por tracción animal; entre 1896 y 1898 la empresa fue capitalizada por banqueros ingleses (Wernher, Beit \& Co.) y transformada en Mexican Electric Tramways Ltd. para transitar hacia la tracción eléctrica del sistema. ${ }^{118}$ Hacia 1896 estas dos empresas, de capital británico, eran dominantes pero no estaban solas. Convivían con ellas varias

línea] http://www.ub.edu/geocrit/cCapel_Innovacion_intro.pdf [27 de enero de 2015].

115 Nicolau d'Olwer, a partir de 1965, y detrás de él otros, han alimentado la confusión: Nicolau D’Olwer, “Las inversiones extranjeras”, p. 1087.

116 A veces las confusiones se derivan de omisiones o cambios sencillos, como una palabra en el nombre de la empresa (por ejemplo: Compañía de Gas por Compañía Mexicana de Gas, o Mexican Tramways por Mexico Tramways), otras por poca atención, por intereses parciales o por falta de información.

117 Rodríguez Kuri, La experiencia olvidada, p. 185.

118 Wilkins, Hausman, Neles, Hertner y Lanthier, "Every city”, p. 113. 
compañías, a veces con dominio de capital mexicano, que proporcionaban electricidad para fábricas, comercios, particulares y alumbrado público, e incluso otras que tenían convenios con el Ayuntamiento para iluminar unas pocas calles con sistemas de gas, de aceite y de trementina. ${ }^{119}$

Las cosas empezaron a dar un giro en 1896. Al final de ese año el Ayuntamiento de la ciudad de México firmó un contrato con la compañía Siemens \& Halske para que se hiciera cargo de la parte principal del alumbrado público urbano e hiciera nuevas instalaciones. Un año después, y como indicaban las reglas financieras del momento, se constituyó en Londres una Fsc, la Mexican Electric Works Limited (con la subsidiaria Compañía Mexicana de Electricidad S.A.), capitalizada principalmente por el Dresdner Bank (que también poseía el Banco Germánico de la América del Sur y apoyó como prestamista a Schöndube en algunas empresas), ${ }^{120}$ y la propia Siemens. El nuevo alumbrado entró formalmente en operación en febrero de 1898, bajo la gerencia del austríaco Franz Neugebauer, de quien mucho se ha dicho en este texto. ${ }^{121}$ En este contexto, los intereses alemanes desplazaron a los ingleses de la Compañía de Gas y Luz Eléctrica (que se reservaron la producción de la energía comercial e industrial) y parecían camino a afincarse con fuerza en el negocio.

La importancia de la Siemens en la prestación del servicio eléctrico en México, aunque relativamente fugaz, no debe soslayarse. Todo lo contrario: su papel en la generación eléctrica para ciudades mexicanas fue muy relevante e incluyó las instalaciones de Mérida en la península, Monclova en el norte, Toluca y Tulancingo en el centro, y Zamora, Celaya, Irapuato, Pénjamo, Valle de Santiago, San Luis de la Paz en el Bajío, entre otras, incluso

119 Rodríguez Kuri, La experiencia olvidada, pp. 185-215.

120 México Ilustrado-Mexico Ilustrated, s/f y s/p. c. 1901-1902. Riguzzi, "Las relaciones de la banca alemana”, pp. 132-135.

121 Rodríguez Kuri, La experiencia olvidada, pp. 195-200. 
Oaxaca y Guadalajara según una fuente. ${ }^{122}$ Además, su negocio, como el de la AEG a través de Schöndube, fue la instalación de plantas para fábricas y la venta de maquinaria y equipo por toda la república. No sabemos hasta cuándo y en qué circunstancias la Siemens se mantuvo produciendo energía eléctrica en las ciudades mencionadas, a excepción de Mérida, cuya planta y concesión traspasó en 1913, ${ }^{123}$ pero lo que ocurrió en la ciudad de México fue indicio de su retiro progresivo del país.

El nuevo giro, mucho más violento, se fue gestando hacia 1902 y estaba totalmente perfilado en 1906 en favor de los intereses canadienses y su respaldo financiero británico. Mientras los tres grandes grupos de empresas que aquí se estudian con especial énfasis estaban hacia 1910 en un momento de franca expansión de sus intereses mexicanos, la Siemens estaba achicando su presencia; de no haber sido así, habría sido un contendiente principal en la lucha de fuerzas por la concentración del negocio.

Como han dicho Armstrong y Nelles, los canadienses, y en general los grandes inversionistas de electricidad en este momento, buscaban "mercados urbanos con razonable abundancia de población", y teniendo como ideal "que hubiera en las cercanías una fuente explotable de fuerza hidroeléctrica”. ${ }^{124}$ El primer paso fue obtener la concesión de la hidroeléctrica de Necaxa en 1902 -el núcleo de su emporio- a partir de la constitución de la Mexican Light and Power Company, en Canadá. En abril de 1903 adquirieron la Compañía Mexicana de Electricidad, de Siemens, y en mayo de 1905 "era un hecho" que absorberían la Compañía Mexicana de Gas y Luz Eléctrica. En el papel, las jugadas necesarias estaban hechas para ganar la partida. Al tiempo que avanzaban las colosales obras de ingeniería en la presa de Necaxa, Frederick Pearson y sus

\footnotetext{
122 México Ilustrado-Mexico Ilustrated, s/f y s/p. c. 1901-1902.

123 Durán-Merk, "Imaginando el progreso”, p. 19.

124 Armstrong y Nelles, “La empresa corporativa”, p. 128.
} 
inversionistas dieron los pasos siguientes. Adquirieron empresas menos grandes pero importantes en el mercado, como la Compañía Explotadora de las Fuerzas Hidroeléctricas de San Ildefonso (mediante una subsidiaria, la Mexican Electric Light Company Limited-Compañía Mexicana de Luz Eléctrica). Sólo hacía falta absorber a la empresa de tranvías, la Mexican Electric Tramways Ltd. Para lograrlo Pearson enfrentó la oposición de sus socios, así que constituyó de forma independiente, con sólo algunos de sus sostenedores pero con nuevos fondos, la Mexico Tramways Company Limited, en 1906.125 "Sólo al cabo de un áspero conflicto se enlazaron formalmente la compañía de tranvías y la de fuerza eléctrica en 1909 (aunque siguieron siendo entidades jurídicas separadas)...". ${ }^{126}$

Como quiera, en 1909 Frederick Pearson y sus inversionistas lograron "el dominio absoluto" de la producción de energía para la ciudad de México y el centro del país, donde producían al menos 100000 caballos de fuerza, uniendo en su portafolio, entre muchas otras, a la Compañía de Luz y Fuerza de Pachuca, la Compañía de Luz y Fuerza Eléctrica de Toluca, la Compañía de Luz y Fuerza de El Oro y más. ${ }^{127}$

Su dominio hasta este momento, hay que subrayarlo, fue enorme pero limitado al centro del país. A su lado estaban otros grupos dominantes en regiones de importancia: Pearson en el Golfo, ligado a los negocios portuarios y petroleros; el всм en Guadalajara y su atractivo mercado urbano e industrial; otras

125 Armstrong y Nelles, "La empresa corporativa”, pp. 130-131. Rodríguez Kuri, La experiencia olvidada, pp. 203-208. Liehr y Torres, "Las compañías eléctricas extranjeras", pp. 21-24.

126 Armstrong y Nelles, “La empresa corporativa”, p. 131.

127 López, Los servicios públicos, p. 269. LieHr y Torres, Las compañias eléctricas, pp. 24-26. Reinhard Liehr y Mariano Torres, "From free-standing company to public enterprise: the Mexican Light and Power Company and the Mexican Tramways Company, 1902-1965", ponencia presentada en el XIII Congreso Internacional de Historia Económica, Buenos Aires, julio del 2002, eh.net/XIIICongress/cd/papers/23LiehrTorres165.pdf 
inversiones canadienses en las zonas mineras del norte (la Mexican Northern Power Co.) o en Guanajuato y sus alrededores.

Con una estrategia empresarial, técnica y financiera muy definida, lograron, en la misma ruta trazada por la Bancaria, a veces por Pearson y por Schöndube, y por muchos otros en el mundo, obligar, acorralar a sus competidores para que les vendieran y hacer crecer sus intereses de modo que fueran, al menos en la pretensión, altamente rentables. Por lo demás, el dominio que la Mexican obtuvo en 1909 selló significativamente el triunfo de la industria y los intereses económicos de Estados Unidos y Canadá sobre los alemanes.

EPÍLOGO. MÁS ALLÁ DEL HORIZONTE DE LAS REDES: CONCENTRACIÓN EMPRESARIAL EN ENTREDICHO Y DIFICULTADES DE LAS CIUDADES PARA CONTAR CON SERVICIOS PÚBLICOS

Medir el grado de concentración alcanzado por las grandes empresas de servicios públicos en México hacia 1910 no es del todo sencillo. Si se evaluara por número de ciudades no tendríamos una imagen contundente. De una parte, sabemos que en 1900 unas 65 ciudades en México contaban con alumbrado público eléctrico y al final de la década se habrían añadido quizá algunas decenas. De otra, existe constancia de que la Mexican Light and Power Company solo dominaba entonces el sector eléctrico de tres ciudades principales: Ciudad de México, Pachuca y Toluca. De los intereses de Weetman Pearson dependía la electrificación de cinco ciudades importantes. Sumado el número de ciudades en que Schöndube, la Bancaria y el Banco Central tuvieron injerencia directa en la construcción o prestación de servicios de alumbrado, tranvías, agua, drenaje, pavimentación y edificios públicos resultan unas 15 urbes diferentes.

Como se ve, numéricamente las tres juntas no eran dominantes, pero ese no es el indicador adecuado. La Mexican Light era 
dueña de toda la región del Valle de México, incluyendo la electrificación de innumerables centros mineros y fábricas. Pearson controlaba un área fundamental que incluía los dos principales puertos del país (Veracruz y Tampico), y dos ciudades industriales y populosas (Puebla y Orizaba), además de que tendió redes de agua y drenaje al menos en otros tres puertos (Coatzacoalcos, Salina Cruz y Mazatlán). Schöndube, la Bancaria y el Central tenían presencia en Guadalajara, Puebla, Querétaro, San Luis Potosí, Morelia, Aguascalientes y otras ciudades en el norte, escapando sólo Monterrey de entre las más pobladas. ${ }^{128}$ Además, Schöndube, y la Bancaria en menor medida, fueron proveedores de muchos de los materiales indispensables para la construcción e instalación de servicios, ya eléctricos, tuberías o pavimentos y asfaltos. En total, las tres firmas aparecieron en obras y servicios de unas 25 o 30 ciudades, eso sí, las más grandes del país (véase el mapa 1).

Teniendo a la vista sólo el sector eléctrico, Moisés Gámez ha argumentado contra las versiones generalizantes según las cuales las empresas que empezaron como pequeñas habrían sido controladas por las grandes. ${ }^{129}$ Hay que poner de relieve esas variedades y complejidades, pero son innegables los alcances de los grandes grupos empresariales (por ejemplo en el sector telefónico, que aquí no se trata, pero donde hubo dos empresas más claramente hegemónicas) e igualmente importante entenderlos con nuevos datos e interpretaciones más de conjunto como la que aquí se presenta. Respecto al agua potable, Diana Birrichaga encontró pocos casos de concentración empresarial en los esquemas de concesión del servicio; ahí figura por ejemplo el empresario William H. Walker, que en 1904 obtuvo concesiones

128 Todo indica que, a partir de 1905, los servicios de agua, drenaje, luz eléctrica y transporte fueron dominados en Monterrey por la Monterrey Railway, Light and Power Company y los intereses canadienses que la controlaban. Véase LieHr y Torres, Las compañias eléctricas, pp. 29-30.

129 GÁmEz (coord.), Electricidad, pp. 14-17. 
en Mérida y en Monterrey, aunque en los siguientes años las traspasó. ${ }^{130}$ En realidad hubo más, donde las empresas de electricidad se hicieron cargo del bombeo y de las actividades alternas del servicio, pero sobre todo existió la concentración, como se ha documentado aquí ampliamente, en la contratación de obras para prestar el servicio.

Conviene añadir dos elementos. Por una parte, junto con las empresas aquí seguidas podrían anotarse ejemplos adicionales de empresas que hasta 1910 no ganaron tanta notoriedad pero que estaban siguiendo caminos semejantes y tuvieron alcances intermedios, al menos regionales. Por lo que se refiere a la producción de energía eléctrica, uno de los casos más relevantes es el de los intereses del banquero estadounidense William P. Bonbright, quien desde sus empresas del sector eléctrico en Colorado, un importante centro minero, controlaba la Michoacan Power Company, la Guanajuato Power Company, y con éxitos desiguales trató de abrazar los territorios vecinos de San Luis Potosí, Aguascalientes y Zacatecas. ${ }^{131}$ Otro conglomerado empresarial fue el de la Compañía Industrial de Orizaba (CIDOSA), que además de sus cuatro grandes fábricas textiles era propietaria de tres hidroeléctricas en su área de influencia. Su caso puede equipararse al de la Compañía Industrial de Guadalajara, que desde sus negocios relacionados con el comercio y fabricación de ropa se extendió a la electricidad, el alumbrado y los tranvías. Sin embargo, mientras cidosa mantuvo sus intereses, la de Guadalajara fue absorbida, según se anotó, por el Banco Central Mexicano, mediante la Compañía Hidroeléctrica de Chapala. En lo que toca a otros servicios, es posible identificar empresas que probaron suerte en más de una ciudad, varias constructoras que obtuvieron contratos por aquí y por

130 BirrichagA, “Las empresas de agua potable”, pp. 210-213.

131 Martínez, Cambio y proyecto urbano, pp. 185-186. LieHr y Torres, “Las compañías eléctricas extranjeras”, p. 29. 
allá, compañías organizadas para gestionar créditos a los gobiernos, pero ninguna alcanzó hasta 1910 el estatus de contendiente mayor, como las tres aquí analizadas.

Además de lo anterior, debe considerarse también que las empresas estudiadas estaban en expansión; el desarrollo que estaba construyendo una compañía como la Bancaria apuntaba sin duda a una ampliación de sus redes: era claro que tenían un proyecto ambicioso en ese sentido. La concentración estaba en un franco ascenso, era un proceso, no un hecho consumado.

La revolución que inició en 1910, sin embargo, introdujo en el panorama de suyo complejo giros inesperados. Por al menos una década hubo una profunda inestabilidad que afectó a las empresas (a unas más que a otras), al cumplimiento de sus compromisos y en la merma de sus beneficios. Lo sucedido entonces rebasa los alcances de este artículo, pero conviene al menos anotar algunos aspectos. Por un buen tiempo, en varios de los servicios se manifestó un repliegue de las empresas; aquí el camino se desandó y se ajustaron los mecanismos de proveeduría de materiales y construcción de obras, siendo el mercado para las empresas pequeñas y medianas.

La suerte fue dispareja. Los negocios de Weetman Pearson como contratista de obras públicas fueron desactivados desde 1911 (aunque aún después su negocio petrolero conoció éxitos insospechados) y las condiciones le fueron más adversas cuando Estados Unidos reconoció al gobierno de Venustiano Carranza, pues Pearson había facilitado la salida de Porfirio Díaz del país y había intervenido con el gobierno británico en el reconocimiento de Victoriano Huerta como cabeza del gobierno de México. ${ }^{132}$ No obstante, Pearson también alcanzó un estadio superior para sus negocios cuando en 1922 formó el holding eléctrico Whitehall Electric Investments, que poco después de

132 Bud Frierman, Godley, Wale, “Weetman Pearson”, pp. 295-297. ConNOLLY, El contratista, pp. 13-14. 
su muerte, ocurrida en $1927,{ }^{133}$ se vendió (en 1929) a la American and Foreign Power Company, el gran holding neoyorkino dueño de la General Electric. La del Banco Central Mexicano y la Bancaria fue una historia diferente: el primero entró en quiebra técnica en 1914 y la segunda se declaró disuelta un poco antes, en diciembre de 1913, alegando "quebrantos de consideración por circunstancia inevitables” y declarando que su capital había tenido "una pérdida de un 50\%". ${ }^{134}$ En algunas ciudades, como en Aguascalientes, se decretó la invalidez de todos los contratos celebrados con esta empresa y por tanto se suspendió el pago del empréstito contratado con el Central. En otros lugares simplemente se dejaron de cubrir las obligaciones adquiridas. ${ }^{135}$ Enrique Schöndube y sus intereses también se vieron mermados por la marea revolucionaria; se replegó a su hacienda La Esperanza, donde emprendió nuevos negocios hasta su trágica muerte en 1927.

Pasada la tempestad se hicieron evidentes otras condiciones. Se conoce bien lo ocurrido respecto a la generación y suministro eléctrico: en este sector, entre 1924 y 1929 se abrió otro ciclo que, esta vez, selló sin margen de duda la concentración empresarial en una nueva escala de expansión del capital. ${ }^{136}$ En otros servicios públicos las cosas fueron distintas, e importa subrayarlo porque la historiografía ha puesto mucho menos atención en ellos que en la electricidad. En la prestación de los servicios de agua o de drenaje, por ejemplo, no existieron las condiciones para la continuidad o la formación de nuevos grupos empresariales dominantes. En las décadas de 1920 y 1930 los gobiernos centrales asumieron como suya la autoridad, y a partir de 1933 el Banco Nacional Hipotecario Urbano y de Obras Públicas se

\footnotetext{
133 LIEHr y TORREs, “Las compañías eléctricas extranjeras”, pp. 34-35.

134 Jiménez, La traza del poder, pp. 139-141.

135 Martínez, Cambio y proyecto urbano, pp. 191-192.

136 Véase, LieHr y TorRes, “Las compañías eléctricas extranjeras”.
} 
destinó a otorgar créditos para todas las construcciones urbanas y obras de servicios públicos.

Para las ciudades la introducción de servicios públicos modernos apareció en 1910 como una suerte de espejismo. Con el fin del porfiriato y el destino de la Bancaria, varias ciudades donde estaba haciendo trabajos tuvieron que esperar una década o más para que se implementaran en algunas de sus calles, por primera vez, las instalaciones de drenaje y la pavimentación. Las ciudades que lograron contar con una red de agua la mantuvieron insuficiente o modestamente, siempre con carencias. El servicio de alumbrado fue deficiente, menudeaban las quejas de la población. Los tranvías eléctricos de muchas ciudades no soportaron la competencia de los autobuses. Al final de la década de 1920, con la excepción de la energía eléctrica y la telefonía, las ciudades mexicanas estaban relativamente fuera del área de influencia de las grandes empresas que habían pretendido dominar los servicios.

\section{SIGLAS Y REFERENCIAS}

AHDF Archivo Histórico del Distrito Federal, Planoteca, Ciudad de México.

AHEA Archivo Histórico del Estado de Aguascalientes, fondos Protocolos Notariales (FPN), Poder Legislativo (PL) y Secretaría General de Gobierno (SG), Aguascalientes, México.

AHMC Archivo Histórico del Municipio de Colima, Libros de Actas de Cabildo, Colima, México.

AHUG Archivo Histórico de la Universidad de Guanajuato, fondo Familia Ponciano Aguilar, Guanajuato, México.

AMA Archivo Municipal de Aguascalientes, fondos Histórico $(H)$ e Impresos (I), Aguascalientes, México.

CEHM-CARSO Centro de Estudios de Historia de México carso, Colección José Yves Limantour, Ciudad de México, México.

MMOyB Mapoteca Manuel Orozco y Berra, SAgarpa, Ciudad de México, México. 
Alfaro Rodríguez, Evelyn, "La ciudad en torno al agua. El arroyo de la Plata como eje simbólico en el ordenamiento urbano de Zacatecas", tesis de doctorado en Historia, Zamora, El Colegio de Michoacán, 2011.

Anaya Merchant, Luis, "La crisis internacional y el sistema bancario mexicano, 1907-1909”, en Secuencia, 54 (sep.-dic. 2002), pp. 154-186.

AÑonve Baños, Manuel, Servicios públicos municipales, México, Porrúa, 1998.

Arizpe, Rafael R., Estadística de las aplicaciones de la electricidad en la República Mexicana, México, Tipografía y Lit. "La Europea”, de J. Aguilar, 1900.

Armstrong, Christopher y Vivien H. Nelles, "La empresa corporativa en el sector de servicios públicos: el desempeño de las compañías canadienses en México y en Brasil, 1896-1930”, en Marichal (coord.), 1995, pp. 125-144.

Birrichaga Gardida, Diana, "Las empresas de agua potable en México (1887-1930)”, en SuÁrez CorTez (coord.), 1998.

Bud Frierman, Lisa, Andrew C. Godley y Judith Wale, "Weetman Pearson in Mexico and the Emergence of a British Oil Major, 1901-1919", en Business History Review, 84 (verano 2010), pp. 275-300.

Bustamante López, Carlos, "Un perfil urbano del prosperato: la ciudad de Tlaxcala (1885-1911)", en Entorno Urbano. Revista de historia, II: 4 (jul.-dic. 1996), pp. 65-92.

Ceceña, José Luis, México en la órbita imperial. Las empresas transnacionales, México, Ediciones El Caballito, 1970.

Coll-Hurtado, Atlántida y María Teresa Sánchez Salazar, "Minería y electricidad”, en Herrera Canales (coord.), 1998.

Connolly, Priscilla, El contratista de don Porfirio. Obras públicas, deuda y desarrollo desigual, México, El Colegio de Michoacán, Universidad Autónoma Metropolitana, Fondo de Cultura Económica, 1997.

Contreras Cruz, Carlos y Jesús Pacheco Gonzaga, "De la modernización porfiriana a la expansión urbana del México posrevolucionario. Puebla, 18801945”, en Martínez Delgado y Bassols Ricardez (coords.), 2014.

Derry, T. K. y Trevor Williams, Historia de la tecnología, vol. 3 Desde 1750 hasta 1900 (II), México, Siglo Veintiuno Editores, 1977. 
Domínguez Rascón, Alfonso, La política de reforma agraria en Chibuabua, 1920-1924. Sus efectos hasta 1940, México, Plaza y Valdés, Instituto Nacional de Antropología e Historia, 2003.

Durán-Merk, Alma, "Imaginando el progreso: la empresa eléctrica Siemens \& Halske en Mérida, Yucatán, México", en Istmo. Revista virtual de estudios literarios y culturales centroamericanos (sección proyectos), 27-28 (jul.-dic. 2013, ene.-jun. 2014), 26 pp.

Fuentes Gómez, José y Magnolia Rosado Lugo, “Auge, consolidación y estancamiento en la construcción del espacio urbano de Mérida: 1800-1975”, en Martínez y Bassols (coords.), 2014, p. 49.

Galarza, Ernesto, La industria eléctrica en México, México, Fondo de Cultura Económica, 1941.

Gamboa Ojeda, Leticia, "El financiamiento de la urbanización. La deuda interior del Ayuntamiento de Puebla en los mercados extranjeros, 1907-1914", en Secuencia. Revista de Historia y Ciencias Sociales, 23 (mayo-ago. 1992), pp. 99-123.

GÁMEZ, Moisés (coord.), Electricidad: recurso estratégico y actividades productivas. Procesos de electrificación en el norte de México, siglos XIX-XX, México, El Colegio de San Luis, 2013.

Garner, Paul, Leones británicos y águilas mexicanas. Negocios, política e imperio en la carrera de Weetman Pearson en México, 1889-1919, México, Fondo de Cultura Económica, El Colegio de México, El Colegio de San Luis, Instituto Mora, 2013.

Gómez Serrano, Jesús y Enrique Rodríguez Varela, Aguascalientes: imperio de los Guggenheim, México, Fondo de Cultura Económica, Secretaría de Educación Pública, 1982, sep Ochentas, 43.

Gómez Serrano, Jesús, “Los extranjeros como agentes y beneficiarios del progreso en Aguascalientes, 1894-1910”, en Eslabones. Revista semestral de estudios regionales, 10 (dic. 1995), pp. 56-69.

GutiérRez Grageda, Blanca Estela, “Infraestructura hidráulica en Querétaro durante el porfiriato", en Julio César Schara, Cuencas hidráulicas, Querétaro, Universidad Autónoma de Querétaro, 2017. 
Hernández Larrañaga, Javier, Guadalajara: identidad perdida. Transformación urbana en el siglo XX, Guadalajara, Impre Jal, 2018.

Herrera Canales, Inés (coord.), La minería mexicana. De la colonia al siglo XX, México, Instituto Mora, El Colegio de Michoacán, El Colegio de México, Universidad Nacional Autónoma de México, 1998.

Новsвашм, Eric, La era del imperio, 1875-1914, Barcelona, Crítica.

Hurtado Hernández, Edgar, “La ciudad sedienta, 1810-1910”, en Edgar HuRTADO (coord.), La ciudad ilustrada: sanidad, vigilancia y población, siglos XVIII y XIX, México, Universidad Autónoma de Zacatecas, 2011, pp. 63-90.

Jiménez Muñoz, Jorge H., La traza del poder. Historia de la política y los negocios urbanos en el Distrito Federal de sus orígenes a la desaparición del Ayuntamiento (1824-1928), México, Gobierno del Distrito Federal, Secretaría de Cultura del Distrito Federal, Universidad Autónoma de la Ciudad de México, 2012.

Jones, Geoffrey, "Business Enterprises and Global Worlds", en Enterprise E Society, 3 (dic. 2002), pp. 581-605.

Kuntz Ficker, Sandra y Priscilla Connolly (coords.), Ferrocarriles y obras públicas, México, Instituto Mora, El Colegio de Michoacán, El Colegio de México, Universidad Nacional Autónoma de México, 1999.

Kuntz Ficker, Sandra y Reinhard Liehr (eds.), Estudios sobre la historia económica de México. Desde la época de la independencia hasta la primera globalización, México, El Colegio de México, Iberoamericana-Vervuert, 2014.

LIEHR, Reinhard y Mariano E. Torres (coords.), Las compañias eléctricas extranjeras en México, 1880-1960, Puebla, Benemérita Universidad Autónoma de Puebla, 2010.

LieHr, Reinhard y Mariano E. Torres, "Formas y estrategias de expansión de las empresas multinacionales eléctricas alemanas en México, 1894-1942", en LieHr y TorRes (coords.), 2010.

LieHr, Reinhard y Mariano E. TorRes, "Las compañías eléctricas extranjeras y la modernización urbana e industrial de México, 1880-1960", en LieHr y Torres (coords.), 2010, pp. 17-66. 
Lira, Carlos, “Obra y servicios públicos en Oaxaca, 1876-1911”, en KunTz Ficker y CoNNOlly (coords), 1999, pp. 220-259.

Lira Vásquez, Carlos y Danivia Calderón Martínez, "De capital estatal a parque temático patrimonio de la humanidad. Oaxaca, 1800-2000”, en MARTíNEZ y Bassols (coords.), 2014.

Lizama Silva, Gladys, "Francisco Martínez Negrete Alba, 1848-1906: una biografía empresarial tapatía”, en América Latina en la Historia Económica, 26 (jul.-dic. 2006), pp. 79-107.

LiZAma SiLva, Gladys, Zamora en el porfiriato: familias, fortunas y economía, México, El Colegio de Michoacán, H. Ayuntamiento de Zamora, 2000.

López Rosado, Diego G., Los servicios públicos de la ciudad de México, México, Porrúa, 1976.

Ludlow, Leonor, "La formación del Banco Nacional de México", en LudLOW, y MARICHAL (coords.), 1998, pp. 142-180.

Ludlow, Leonor y Carlos Marichal (coords.), La banca en México, 18201920, México, Instituto Mora, 1998.

Marichal, Carlos (coord.), Las inversiones extranjeras en América Latina, 1850-1930. Nuevos debates y problemas en historia económica comparada, México, El Colegio de México, Fondo de Cultura Económica, 1995.

Martínez Delgado, Gerardo, Cambio y proyecto urbano. Aguascalientes 1880-1914, Aguascalientes, Universidad Autónoma de Aguascalientes, Fomento Cultural Banamex, Pontificia Universidad Javeriana, 2009.

Martínez Delgado, Gerardo y Mario Bassols Ricardez (coord.), Ciudades poscoloniales en México. Transformaciones del espacio urbano, México, Benemérita Universidad Autónoma de Puebla, 2014.

Medina Lozano, Lidia, El tránsito urbano hacia la modernidad. Proceso de transformación en Zacatecas (1877-1910), Zacatecas, Texere, 2012.

Meyer Cosío, Francisco Javier, "La ciudad de Guanajuato a principios del siglo xx. Una hegemonía en entredicho”, en Muro González (coord.), 1998, pp. 45-64. 
Muro González, Víctor Gabriel (coord.), Ciudades provincianas de México: historia, modernización y cambio cultural, Zamora, El Colegio de Michoacán, 1998.

Nicolau D’Olwer, Luis, “Las inversiones extranjeras”, en Daniel Cosío Villegas (director), Historia Moderna de México. El Porfiriato, Vida económica, México, Editorial Hermes, 1965, vol. 2. pp. 1086-1185.

Noriega Caldera, María Guadalupe, "Más allá de la minería: empresas y empresarios de la industria fabril en Zacatecas durante el Porfiriato (18771911)”, tesis de maestría en historia, El Colegio de San Luis, 2014.

OÑATE, Abdiel, "La crisis de 1907-1908 y el sistema bancario mexicano", en LudLOW y MARICHAL (coords.), 1998, pp. 181-200.

Osterhammel, Jürgen, La transformación del mundo. Una historia global del siglo XIX, Barcelona, Crítica, 2015.

Parra, Alma, "Lord Cowdray y la industria eléctrica en México", en LieHr y TORRES (coords.), 2010, pp. 107-144.

Pérez Acevedo, Martín, Empresarios y empresas en Morelia, 1860-1910, Morelia, Universidad Michoacana de San Nicolás de Hidalgo, 1994.

Preciado Zamora, Julia, "Los cristeros del volcán y los pacíficos de La Esperanza”, Signos Históricos, 19 (ene.-jun. 2008), pp. 68-93.

Puente Zubiaur, Orlando y Rafael Soldara Luna, "La bola de agua" [en línea] https://computec1618.wordpress.com/division-porfirista-guanajuato/ la-bola-de-agua/ [27 de febrero de 2019].

Ramos Navas, Germán, El comercio eléctrico en Guadalajara, Guadalajara, Ágata, 2000.

Riguzzi, Paolo, "Las relaciones de la banca alemana con México, 1887-1913. ¿Deuda, inversiones y poder financiero?”, en KunTz Ficker y LieHr (eds.), 2014, pp. 109-144.

Rodríguez KuRI, Ariel, “Gobierno local y empresas de servicios: la experiencia de la ciudad de México en el Porfiriato”, en Kuntz Ficker y Connolly (coords.), 1999, pp. 165-190. 
Rodríguez Kuri, Ariel, La experiencia olvidada. El Ayuntamiento de México:política y gobierno, 1876-1912, México, El Colegio de México, Universidad Autónoma Metropolitana-Azcapotzalco, 1996.

Sánchez Díaz, Gerardo (coord.), Pueblos, villas y ciudades de Michoacán en el porfiriato, Morelia, Universidad Michoacana de San Nicolás de Hidalgo, 1991.

SÁnchez García, Juan Hugo, "Gobierno municipal, relaciones ciudadcampo y modernidad: Oaxaca, 1890-1912", tesis de doctorado en historia, Zamora, El Colegio de Michoacán, 2013.

Series Históricas INEGI, 1895-1995 [en línea]. www.inegi.gob.mx [20 de julio de 2005].

Silva Mandujano, Gabriel, “Ario de Rosales: 1880-1910”, en Sánchez Díaz (coord.), 1991, pp. 13-25.

SuÁrez Cortez, Blanca E. (coord.), Historia de los usos del agua en México. Oligarquías, empresas y ayuntamientos (1840-1940), México, Comisión Nacional del Agua, Centro de Investigaciones y Estudios Superiores en Antropología Social, Instituto Mexicano de Tecnología del Agua, 1998.

TAmayo, Jorge L., "La generación de energía eléctrica en México", en El Trimestre Económico, 9: 35 (3) (oct.-dic. 1942), pp. 405-439.

Topik, Steven C., "When Mexico had the blues. A transatlantic tale of bonds, bankers, and nationalists, 1862-1910", en The American Historical Review, 105: 3 (jun. 2000), pp. 714-738.

Trentini, Francisco, El florecimiento de México, México, Tipografía de Bouligny \& Schmidt Sucs., 1906.

Uribe Salas, José Alfredo, Morelia: los pasos a la modernidad, Morelia, Universidad Michoacana de San Nicolás de Hidalgo, 1993.

Valerio Ulloa, Sergio, "Empresas, tranvías y alumbrado público. La Compañía Hidroeléctrica e Irrigadora del lago de Chapala”, en Memorias del Segundo Congreso de Historia Económica. La historia económica boy, entre la economía y la historia, México, Universidad Nacional Autónoma de México, 2004 [En línea]. http://www.economia.unam.mx/amhe/memoria/memoria. html [Consultada en mayo 2006]. 
Valerio Ulloa, Sergio, Los barcelonnettes en Guadalajara, siglos XIX y XX, México, Universidad de Guadalajara, Instituto Mora, 2015.

Wilkins, Mira, William Hausman, H. V. Neles, Peter Hertner, Pierre Lanthier, "Every city, 1880-1914”, en William J. Hausman, Peter Hertner y Mira WiLKIns, Global Electrification. Multinational Enterprise and International Finance in the History of Light and Power, 1878-2007, Cambridge, Cambridge University Press, 2008.

Williams, Trevor, Historia de la tecnología, vol. 4: Desde 1900 hasta 1950 (I), México, Siglo Veintiuno Editores, 1987. 